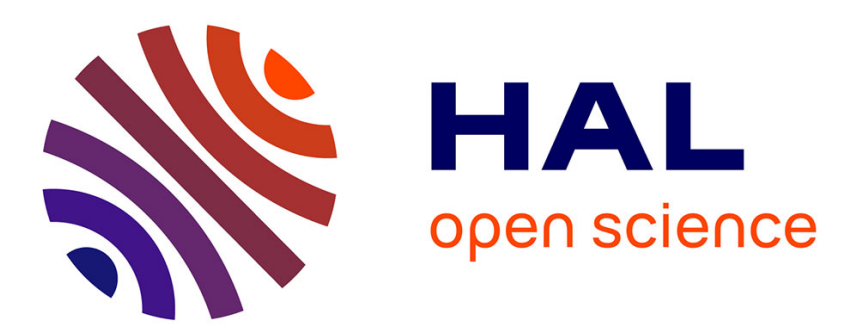

\title{
Far-infrared spectroscopy of heavy protonated noble gas species using synchrotron radiation
}

\author{
Sébastien Gruet, Olivier Pirali
}

\section{To cite this version:}

Sébastien Gruet, Olivier Pirali. Far-infrared spectroscopy of heavy protonated noble gas species using synchrotron radiation. Molecular Physics, 2018, 117 (13), pp.1719-1731. 10.1080/00268976.2018.1564851 . hal-02301119

\section{HAL Id: hal-02301119 \\ https://hal.science/hal-02301119}

Submitted on 5 Sep 2021

HAL is a multi-disciplinary open access archive for the deposit and dissemination of scientific research documents, whether they are published or not. The documents may come from teaching and research institutions in France or abroad, or from public or private research centers.
L'archive ouverte pluridisciplinaire HAL, est destinée au dépôt et à la diffusion de documents scientifiques de niveau recherche, publiés ou non, émanant des établissements d'enseignement et de recherche français ou étrangers, des laboratoires publics ou privés. 


\title{
Far-infrared spectroscopy of heavy protonated noble-gas species using synchrotron radiation
}

\author{
Sébastien Gruet ${ }^{1,2,3}$ and Olivier Pirali ${ }^{1,2}$
}

December 17, 2018

\author{
${ }^{1}$ Institut des Sciences Moléculaires d'Orsay (ISMO), CNRS, Univ Paris Sud, Université \\ Paris-Saclay, F-91405 Orsay, France \\ ${ }^{2}$ AILES beamline, SOLEIL Synchrotron, L'Orme des Merisiers, 91190 Saint-Aubin, France \\ ${ }^{3}$ Present address: Université Lille, CNRS , UMR 8523 - PhLAM - Physique des Lasers Atomes et \\ Molécules, F-59000 Lille, France.
}

\begin{abstract}
In this work, we report new absorption spectra of protonated noble-gas species $\mathrm{ArH}^{+}$, $\mathrm{KrH}^{+}$, and $\mathrm{XeH}^{+}$. Both pure rotation transitions and rotation-vibration transitions were recorded at high resolution using the Fourier transform interferometer of the AILES beamline of the synchrotron facility SOLEIL. The species were produced in a "hollow cathode" discharge cell for which the cathode is cooled down to liquid nitrogen temperature. While our spectra of $\mathrm{ArH}^{+}$do not provide new experimental information compared to the wealth of data available in the literature, both spectra of $\mathrm{KrH}^{+}$and $\mathrm{XeH}^{+}$contain numerous new transitions belonging to several isotopologues observed in natural abundance. $\mathrm{KrH}^{+}$and $\mathrm{XeH}^{+}$spectra have been analyzed using a Dunham Hamiltonian to provide mass independent sets of parameters and allowing to determine bond lengths with improved accuracy.
\end{abstract}

To whom correspondence should be addressed: sebastien.gruet@univ-lille.fr, olivier.pirali@synchrotronsoleil.fr 


\section{Introduction}

Since the first identification of the $\mathrm{CH}$ radical species in the interstellar medium in 1937 by Swings and Rosenfeld [1], more than 200 molecules have been unambiguously detected in space, and among them, more than a third are radical or ionic species.[2] The relatively high chemical reactivity of these molecules make them primary species implied in numerous chemical-physics processes of astrophysical environments. Improving the understanding of these processes requires to detect and to quantify molecular abundances, and in particular, those of chemically reactive species. In this context, protonated noble-gas $\left(\mathrm{NgH}^{+}\right)$species $\left(\mathrm{HeH}^{+}, \mathrm{NeH}^{+}, \mathrm{ArH}^{+}, \mathrm{KrH}^{+}\right.$, and $\left.\mathrm{XeH}^{+}\right)$constitute an interesting class of molecules for astrophysics illustrated by the detection of ${ }^{36} \mathrm{ArH}^{+}$by Barlow et al. [3] using observation data from the Herschel satellite. Moreover, Schilke et al. [4] demonstrated that variations of column densities of $\mathrm{ArH}^{+}$(together with other light molecular hydrides) could be considered as useful tracers of $\mathrm{H}_{2}$ as well as atomic gas abundances in specific environments. To date, $\mathrm{ArH}^{+}$is the only molecule belonging to the $\mathrm{NgH}^{+}$family detected in space; $\mathrm{HeH}^{+}$, suspected to play a crucial role in the chemistry of the universe, is still to be observed. [5, 6]

The detection of chemically reactive species in astrophysical observations relies on the ability to accurately measure their spectra in the laboratory over a large spectral region. Because of their interest for astrophysics, $\mathrm{NgH}^{+}$species have been the subject of many spectroscopy papers over past decades. In this paragraph, we report on the major sources of data concerning the $\mathrm{ArH}^{+}, \mathrm{KrH}^{+}$, and $\mathrm{XeH}^{+}$species and their isotopologues (see table1). $\mathrm{ArH}^{+}$ is the first $\mathrm{NgH}^{+}$molecule observed in the laboratory: Brault and Davis [7] used a Fourier transform infrared (FTIR) interferometer to record its mid-infrared (mid-IR) emission from a hollow cathode discharge cell. From the emission spectrum, the authors identified the fundamental vibrational mode of ${ }^{40} \mathrm{ArH}^{+}$as well as many hot band sequences involving vibrational states up to $v=5$. FTIR emission spectroscopy was also used by Johns [8] to record new data on $\mathrm{ArH}^{+}$and $\mathrm{KrH}^{+}$, and by Rogers et al. [9] to provide the rotation-vibration spectrum of $\mathrm{XeH}^{+}$. In addition to the work of Brault and Davis [7], Johns measured two more hot bands of ${ }^{40} \mathrm{ArH}^{+}(v=6 \rightarrow 5$ and $v=7 \rightarrow 6)$ together with three bands of ${ }^{40} \mathrm{ArD}^{+}$ $(v=1 \rightarrow 0,2 \rightarrow 1,3 \rightarrow 2)$ and two bands of $\operatorname{KrH}^{+}(v=1 \rightarrow 0,2 \rightarrow 1)$ involving 5 of the 6 stable isotopologues of $\mathrm{Kr}$. Concerning $\mathrm{XeH}^{+}$, Rogers published two rovibrational bands $(v=1 \rightarrow 0,2 \rightarrow 1)$ of the three most abundant isotopologues $\mathrm{XeH}^{+}(\mathrm{A}(\mathrm{Xe})=129,131,132)$. More recently, Cueto et al. [10] completed the initial work of Filgueira and Blom [11] by 
recording several transitions of ${ }^{36} \mathrm{ArH}^{+}$and ${ }^{38} \mathrm{ArH}^{+}$in natural abundance $(0.3 \%$ and $0.06 \%$, respectively) using laser spectroscopy in the mid-IR region. To our knowledge, there is no experimental mid-IR data concerning the less abundant isotopologues ${ }^{36} \mathrm{ArD}^{+}$and ${ }^{38} \mathrm{ArD}^{+}$.

In the submillimeter range, numerous data have been obtained regarding pure rotation transitions of $\mathrm{NgH}^{+}$species in their ground vibrational state (GS, table 1 . As an example, the $J=1 \leftarrow 0$ fundamental transition of ${ }^{40} \mathrm{ArH}^{+}$was first measured by Brown et al. [12] in 1988 and recently, Bizzocchi et al. [13] accurately measured this fundamental transitions for ${ }^{36} \mathrm{ArH}^{+}$and ${ }^{38} \mathrm{ArH}^{+}$, the astrophysically relevant isotopologues of the species. Identical transitions of $\mathrm{ArD}^{+}, \mathrm{KrD}^{+}$, and $\mathrm{XeH}^{+}$were studied by Bowman et al. [14], Warner et al. [15] and Peterson et al. [16], respectively. Ting and Amano [17] completed the $\mathrm{XeH}^{+}$and $\mathrm{XeD}^{+}$ spectra by recording $J=2 \leftarrow 1$ transition of $\mathrm{XeH}^{+}$as well as the $J=3 \leftarrow 2$ and $J=4 \leftarrow 3$ transitions of $\mathrm{XeD}^{+}$. In addition to these transitions measured in the submillimeter region, several groups developed in the 90's tunable far-infrared (far-IR) sources to extend the pure rotation dataset of numerous light hydrides in the THz.[12, 18-21] For instance, Linnartz et al. [19] and Odashima et al. [20] observed pure rotation transitions of the three most abundant protonated krypton isotopologues (involving $\mathrm{A}(\mathrm{Kr})=82,84$, and 86 ) up to 3.5 THz with $J_{\max }^{\prime \prime}=6$ and $J_{\max }^{\prime \prime}=13$ for $\mathrm{KrH}^{+}$and $\mathrm{KrD}^{+}$, respectively.

On the AILES beamline of synchrotron SOLEIL, we benefit from the relatively high brilliance of the far-IR synchrotron continuum to record absorption spectra with higher signal to noise ratio $(\mathrm{S} / \mathrm{N})$ than with the conventional sources equipping commercial FT interferometers (e.g. globar and mercury sources). We used this radiation together with various discharge cells to record absorption spectra of several reactive species. The first setups designed on the beamline allowed us to probe the composition of plasma gas generated by both radio-frequency $(13.6 \mathrm{MHz})$ and DC discharge in a positive column configuration [25]. These experimental set-ups provided new data concerning several light radicals and reactive species such as $\mathrm{NH}_{2}, \mathrm{NH}, \mathrm{OH}, \mathrm{SH}, \mathrm{SO}, \mathrm{S}_{2} \mathrm{O}, \mathrm{C}_{3}$ (e.g. [26, 27]). More recently, we developed a DC discharge absorption cell, for which a hollow cathode configuration allowed us to record spectra of protonated species [28]. The present paper reports new measurements of pure rotation and rotation-vibration transitions of $\mathrm{ArH}^{+}, \mathrm{KrH}^{+}$, and $\mathrm{XeH}^{+}$ using this hollow cathode discharge cell. The second section of the paper contains a rapid description of the experimental set-up together with the experimental conditions found to optimize the production of $\mathrm{ArH}^{+}, \mathrm{KrH}^{+}$and $\mathrm{XeH}^{+}$in our discharge cell. The two theoretical models used to fit the data will be also detailed in this second section. We present in the third section the spectra together with their analysis and fits for the three species studied. 


\begin{tabular}{|c|c|c|c|c|c|c|c|c|}
\hline \multirow[t]{2}{*}{$\mathrm{Ng}$} & \multirow[t]{2}{*}{$\mathrm{A}$} & \multirow[t]{2}{*}{ n.a. ${ }^{a}$} & \multicolumn{3}{|c|}{$J_{\max }^{b}$} & \multicolumn{3}{|c|}{$v_{\max }^{b}$} \\
\hline & & & This work & Previous & Refs. & This work & Previous & Refs. \\
\hline \multirow[t]{3}{*}{$\mathrm{Ar}$} & 36 & 0.3 & $-/-$ & $1 / 1$ & [13, 14] & $-/-$ & $1 /-$ & [10, 11] \\
\hline & 38 & 0.1 & $-/-$ & $1 / 1$ & [13, 14] & $-/-$ & $1 /-$ & [10, 11] \\
\hline & 40 & 99.6 & 7/- & $23 / 14$ & {$[12,14,18,22,23]$} & $1 /-$ & $7 / 3$ & [7, 8, 23, 24] \\
\hline \multirow[t]{6}{*}{$\mathrm{Kr}$} & 78 & 0.3 & $-/-$ & $-/ 1$ & [15] & $-/-$ & $-/-$ & \\
\hline & 80 & 2.3 & $-/-$ & $-/ 1$ & [15] & $-/-$ & $2 /-$ & 8 \\
\hline & 82 & 11.6 & $13 /-$ & $6 / 12$ & [15, 20] & $1 /-$ & $2 /-$ & 8 \\
\hline & 83 & 11.5 & $14 /-$ & $-/ 1$ & [15] & $1 /-$ & $2 /-$ & [8] \\
\hline & 84 & 57.0 & $17 /-$ & $6 / 13$ & [15, 19, 20] & $1 /-$ & $2 /-$ & [8] \\
\hline & 86 & 17.3 & $14 /-$ & $6 / 13$ & [15, 19, 20] & $1 /-$ & $2 /-$ & 8 \\
\hline \multirow[t]{9}{*}{ Xe } & 124 & 0.1 & $-/-$ & $2 / 4$ & [16, 17] & $-/-$ & $-/-$ & \\
\hline & 126 & 0.1 & $-/-$ & $2 / 4$ & [16, 17] & $-/-$ & $-/-$ & \\
\hline & 128 & 1.9 & $-/-$ & $2 / 4$ & [16, 17] & $-/-$ & $-/-$ & \\
\hline & 129 & 26.4 & $11 /-$ & $10 / 9$ & [16, 17, 21] & $1 /-$ & $2 /-$ & 9 \\
\hline & 130 & 4.1 & $-/-$ & $2 / 4$ & [16, 17] & $1 /-$ & $-/-$ & \\
\hline & 131 & 21.2 & $11 /-$ & $9 / 16$ & [16, 17, 21] & $1 /-$ & $2 /-$ & 99 \\
\hline & 132 & 26.9 & $11 /-$ & $8 / 15$ & [16, 17, 21] & $1 /-$ & $2 /-$ & 99 \\
\hline & 134 & 10.4 & $-/-$ & $6 / 7$ & [16, 17, 21] & $1 /-$ & $-/-$ & \\
\hline & 136 & 8.9 & $-/-$ & $6 / 7$ & [16, 17, 21] & $1 /-$ & $-/-$ & \\
\hline
\end{tabular}

${ }^{a}$ Earth' natural abundances of $\mathrm{Ar}, \mathrm{Kr}$, and Xe

${ }^{b}$ The first value refers to the $\mathrm{NgH}^{+}$species and the second one to the $\mathrm{NgD}^{+}$isotopologue

Table 1: Summary of pure rotation and rotation-vibration transitions data set concerning ${ }^{A} \mathrm{NgH}^{+}$and ${ }^{A} \mathrm{NgD}^{+}$— with $\mathrm{Ng}=\mathrm{Ar}, \mathrm{Kr}$, and $\mathrm{Xe}-$ available from the literature and our work. 
Finally the conclusion section contains also some instrumental perspectives to improve the quality of our recordings and extend such studies to other ionic molecules.

\section{Experimental and theoretical details}

\subsection{Experimental details}

A series of experiments on protonated species were realized in the mid-IR and in the far-IR domains on the AILES beamline of the synchrotron facility SOLEIL. A liquid nitrogencooled hollow cathode discharge cell was used to produce the species. Details of the experimental apparatus can be found in Gruet et al. [28]. Briefly, the cell is connected to the high resolution FTIR spectrometer (Bruker IFS 125) of the AILES beamline. The synchrotron radiation extracted by the beamline is directed toward the FTIR spectrometer and used as the far-IR continuum source for absorption spectroscopy. The interaction chamber is a White-type multipass cell in an optical arrangement that allows 20 passes through the discharge volume, hence an absorption pathlength of $24 \mathrm{~m}$. The cell is separated from the FTIR spectrometer by two polypropylene windows (60 $\mu \mathrm{m}$ thickness). Although this material is not conventionally used in the mid-IR region, the transmission in the 1800-2600 $\mathrm{cm}^{-1}$ region allowed for the observation of the rotation-vibration transitions of the cations studied here.

Inside the chamber, the two electrodes (the hollow cathode and the anode) are in a geometrical configuration designed to maximize the so-called negative glow part of the plasma produced by an electrical discharge (see Fig.1 of Gruet et al. [28]). The plasma was resulting from the application of $1 \mathrm{kV}$ potential difference between the two electrodes, with a current value set to $0.85 \mathrm{~A}$. The cryogenic fluid was flowed continuously through a $4 \mathrm{~mm}$ inner diameter copper tube wrapped around the $70 \mathrm{~cm}$ long hollow cathode. The low temperature of the cathode increased the molecular density of cations as observed previously in our study on $\mathrm{HN}_{2}^{+}$[28]. Liquid nitrogen is usually used as the cooling fluid in our experiment. However, for the measurements realized on $\mathrm{XeH}^{+}$, since the melting point of xenon is $161 \mathrm{~K}$, an ethanol bath at a temperature of $193 \mathrm{~K}$ replaced liquid nitrogen. A relatively fast and continuous flow of $\mathrm{Ng}$ and $\mathrm{H}_{2}$ is maintained using a $250 \mathrm{~m}^{3} \cdot \mathrm{h}^{-1}$ roots blower and a roughing pump. Typical pressures are estimated to about $0.1 \mathrm{mbar}$ in the cell. Since the relative pressure of $\mathrm{Ng}$ and $\mathrm{H}_{2}$ is a key parameter in the formation of $\mathrm{NgH}^{+}$in sufficient density to perform FTIR absorption spectroscopy, this parameter is discussed in 
the subsection 2.2

Typical acquisition time necessary to record each far-IR spectra is of about 6 hours. It was mostly limited by the buffer time necessary to cool down the cathode after the acquisition of a set of two successive interferograms. Table 2 summarized other experimental parameters concerning the detectors, beamsplitters, and sources of radiation used to record spectra in each spectral range.

\begin{tabular}{cccccc}
\hline Spectral range & Source & Detector & Beamsplitter & Optical Filter & T Cathode \\
\hline $60-300 \mathrm{~cm}^{-1}$ & Synch. rad. & Bolometer $(4 \mathrm{~K})$ & Mylar $(6 \mu \mathrm{m})$ & $\leq 300 \mathrm{~cm}^{-1}$ & $77 \mathrm{~K}^{*}$ \\
$1800-3000 \mathrm{~cm}^{-1}$ & Globar & InSb $(77 \mathrm{~K})$ & $\mathrm{KBr}$ & $\leq 3000 \mathrm{~cm}^{-1}$ & $77 \mathrm{~K}^{*}$ \\
\hline${ }^{*}$ Except for the acquisition of $\mathrm{XeH}^{+}$spectra for which the temperature was set to about $T=193 \mathrm{~K}$ &
\end{tabular}

Table 2: Technical details used to collect the spectra of protonated rare gases.

The experimental spectra have been calibrated using two sets of references: $\mathrm{H}_{2} \mathrm{O}$ [29] transitions were used to calibrate our far-IR frequencies and $\mathrm{CO}$ [30] transitions were used to calibrate the mid-IR spectra. Both $\mathrm{H}_{2} \mathrm{O}$ and $\mathrm{CO}$ were present as impurities in the spectra.

\subsection{Reaction mechanism}

The protonated species investigated in this study (i.e. $\mathrm{ArH}^{+}, \mathrm{KrH}^{+}$, and $\mathrm{XeH}^{+}$) are produced in the discharge following similar reaction mechanisms based on the ionization of molecular $\mathrm{H}_{2}$ in order to form $\mathrm{H}_{2}^{+}$. $\mathrm{H}_{2}^{+}$is a highly reactive molecule which easily transfers its proton by collision to synthesize protonated species (reaction 1] [31].

$$
\mathrm{H}_{2}^{+}+\mathrm{X} \rightarrow \mathrm{XH}^{+}+\mathrm{H} \text { avec } \mathrm{X}=\left(\mathrm{H}_{2}, \mathrm{Ar}, \mathrm{Kr}, \mathrm{Xe}\right)
$$

The formation of the target protonated species is then highly dependant on the concentration ratio chosen between $\mathrm{H}_{2}$ and the parent atom or molecule. This ratio $\left(\mathrm{P}_{\mathrm{H}_{2}} / \mathrm{P}_{\text {neutral species }}\right)$ is deduced from the proton affinity (PA) of the neutral species, which is the key parameter here. The PA of a few neutral species is reported in Table 3

\begin{tabular}{lcccccc}
\hline Species & $\mathrm{He}$ & $\mathrm{Ne}$ & $\mathrm{Ar}$ & $\mathrm{H}_{2}$ & $\mathrm{Kr}$ & $\mathrm{Xe}$ \\
\hline PA $\left(\mathrm{kJ} . \mathrm{mol}^{-1}\right)$ & 177.8 & 198.8 & 369.2 & 422.3 & 424.6 & 499.6 \\
\hline
\end{tabular}

Table 3: Comparison between the proton affinity of $\mathrm{Ng}$ atoms and $\mathrm{H}_{2}$ molecule.

Case 1: In the case where the PA of the neutral species is lower than $\mathrm{PA}\left(\mathrm{H}_{2}\right)$, the excess of $\mathrm{H}_{2}$ in the plasma should be avoided and an optimal equilibrium is found between the formation of the protonated species (reaction 1 ) and its destruction through reaction 2 


$$
\mathrm{H}_{2}+\mathrm{XH}^{+} \rightarrow \mathrm{H}_{3}^{+}+\mathrm{X}
$$

This is the case for rare gases which possess a PA weaker than $\mathrm{H}_{2}$ (e.g $\mathrm{He}, \mathrm{Ne}$, Ar). Hence, the pressure ratio found in the literature to produce $\mathrm{HeH}^{+}, \mathrm{NeH}^{+}, \mathrm{ArH}^{+}$ is $\mathrm{P}_{\mathrm{H}_{2}} / \mathrm{P}_{\text {neutral species }}<\frac{1}{100}$ [32, 33].

Case 2: In the case where the PA of the neutral species is stronger than $\operatorname{PA}\left(\mathrm{H}_{2}\right)$, then the pressure ratio should be optimized with an excess of $\mathrm{H}_{2}$. This excess reinforces the production of the targeted protonated species with a second reaction pathway involving $\mathrm{H}_{3}^{+}$molecules. In these conditions, $\mathrm{H}_{3}^{+}$is formed during reaction 1 in presence of $\mathrm{H}_{2}$ :

$$
\mathrm{H}_{2}^{+}+\mathrm{H}_{2} \rightarrow \mathrm{H}_{3}^{+}+\mathrm{H}
$$

$\mathrm{H}_{3}^{+}$will then play a role of proton donor with the neutral species according to reaction (4).

$$
\mathrm{H}_{3}^{+}+\mathrm{X} \rightarrow \mathrm{XH}^{+}+\mathrm{H}_{2}
$$

In excess of $\mathrm{H}_{2}$, concentration of $\mathrm{H}_{3}^{+}$increases and, in turn, favors reaction 4 . This second reaction pathway added to reaction 1 boosts the production of the protonated species. Working in an excess of $\mathrm{H}_{2}$ favors the formation of $\mathrm{HN}_{2}^{+}, \mathrm{HCO}^{+}$or $\mathrm{XeH}^{+}$. We note that while the proton affinity of $\mathrm{KrH}^{+}$is almost equal to the one of $\mathrm{H}_{2}$, the strongest signal for $\mathrm{KrH}^{+}$was found when working in excess of $\mathrm{H}_{2}$.

\subsection{Theoretical models}

$\mathrm{NgH}^{+}$molecules are diatomic species with ${ }^{1} \Sigma$ electronic GS. In the case of $\mathrm{ArH}^{+}, \mathrm{KrH}^{+}$, and $\mathrm{XeH}^{+}$each species possesses several stable isotopologues detected in the spectra (see table 1). For these species, two different theoretical models can be used to fit the experimental dataset.

A first set of parameters was produced by fitting separately the rotation-vibration transitions for each isotopologues with the following effective Hamiltonian:

$$
E(v, J)=v_{v}+B_{v} J(J+1)-D_{v}[J(J+1)]^{2}+H_{v}[J(J+1)]^{3} \pm \ldots
$$

where $E(v, J)$ is the energy of the level in the vibrational state $v$ with the rotational 
quantum number $J . B_{v}$ is the rotational parameter, and $D_{v}$ and $H_{v}$ are the centrifugal distortion constants. This equation represents the standard way to fit experimental transitions for a ${ }^{1} \Sigma$ diatomic molecule and we used SPFIT program [34] to perform the fittings. The molecular parameters obtained for $\mathrm{KrH}^{+}$are listed in Table 5 and those for $\mathrm{XeH}^{+}$in Table 8 .

As already mentioned, we observed in the FTIR spectra pure rotation transitions as well as rotation-vibration transitions involving several isotopologues of $\mathrm{KrH}^{+}$and $\mathrm{XeH}^{+}$in natural abundances. In order to analyze all these data simultaneously, we used a Dunham Hamiltonian to obtain a second set of parameters accounting for all isotopologues and vibrational states of a given species. These fits were computed with the dParFit software (v3.3) developed by Robert J. Le Roy (University of Waterloo, CA). [35]

For a diatomic molecule in a ${ }^{1} \Sigma$ electronic state, the rotation-vibration energy levels of one of the isotopologue $\alpha$ can be described by Dunham expansions that in their simplest expression can be expressed as:

$$
E_{D u n}^{\alpha}(v, J)=\sum_{l, m} Y_{l, m}^{\alpha}\left(v+\frac{1}{2}\right)^{l}[J(J+1)]^{m}
$$

where $v$ and $J$ are the quantum numbers for the vibration and the rotation of the molecule, and $Y_{l, m}$ are the Dunham coefficients. In order to treat simultaneously several isotopologues, a general multi-isotopologues Dunham-type level energy expression has been introduced by Ross et al. [36] and Watson [37]:

$$
E^{\alpha}(v, J)=\sum_{l, m} \frac{U_{l, m}}{\left(\mu_{\alpha}\right)^{m+l / 2}}\left(1+\frac{m_{e}}{M_{A}^{\alpha}} \Delta_{l, m}^{A}+\frac{m_{e}}{M_{B}^{\alpha}} \Delta_{l, m}^{B}\right) \times\left(v+\frac{1}{2}\right)^{l}[J(J+1)]^{m}
$$

where $U_{l, m}$ and $\Delta_{l, m}$ are mass-independent parameters, $\mu_{\alpha}$ is the reduced mass of isotopologue $\alpha$ of a molecule from atoms A and B with atomic masses $M_{A}$ and $M_{B}$, respectively, and $m_{e}$ corresponds to the electron mass.

In dParFit v3.3, Robert J. Le Roy implemented a revised formulation of Eq.7 which is described below (Eq. 8). Details about this representation can be found in Refs. [35, 38].

$$
\begin{aligned}
E^{\alpha}(v, J)=\sum_{(l, m) \neq(0,0)} Y_{l, m}^{1}( & \left.\frac{\mu_{1}}{\mu_{\alpha}}\right)^{m+l / 2} \times\left(v+\frac{1}{2}\right)^{l}[J(J+1)]^{m} \\
& +\sum_{(l, m) \geq(0,0)}\left(\frac{\Delta M_{A}^{\alpha}}{M_{A}^{\alpha}} \delta_{l, m}^{A}+\frac{\Delta M_{B}^{\alpha}}{M_{B}^{\alpha}} \delta_{l, m}^{B}\right)\left(\frac{\mu_{1}}{\mu_{\alpha}}\right)^{m+l / 2} \times\left(v+\frac{1}{2}\right)^{l}[J(J+1)]^{m}
\end{aligned}
$$


where $\Delta M_{A}^{\alpha}=M_{A}^{\alpha}-M_{A}^{1}$ and $\alpha=1$ identify the selected reference isotopologue (usually the most abundant isotope of each atom), and $\delta_{l, m}$ are correction coefficients.

From the value of $U_{01}$, the Born-Oppenheimer bond distance can be deduced using the simple relation:

$$
U_{0,1}\left(r_{e}\right)^{2}=505379.0088(1) \mathrm{MHz} \cdot u \cdot \AA^{2}
$$

The conversion constant in Eq. 9 and its error estimate are calculated with values of fundamental constants from the National Institute of Standards and Technology [39].

In the present study, our measurements were injected in a combined analysis containing pure rotation as well as rotation-vibration transitions from the literature to improve the determination of the mass-independant Dunham parameters for the $\mathrm{KrH}^{+}$and $\mathrm{XeH}^{+}$ molecules.

\section{Results and discussion}

In this section we present the pure rotation and rotation-vibration spectra we recorded with our experimental set-up, the results of the combined fits compared to previous results and theoretical calculations, and a short discussion around the determination of the molecular bond lengths.

\subsection{Spectroscopy of $\mathrm{KrH}^{+}$}

$\mathrm{KrH}^{+}$is a diatomic molecule with a calculated permanent dipole moment of about $1.9 \mathrm{D}$ [40]. Linnartz et al. [19] determined that, at the equilibrium geometry, the bond length is to $r_{e}^{B O}=$ 1.4211904(5) А̊. $\mathrm{KrH}^{+}$possesses six stable isotopologues: ${ }^{78} \mathrm{KrH}^{+}(0.35 \%),{ }^{80} \mathrm{KrH}^{+}(2.25 \%)$, ${ }^{82} \mathrm{KrH}^{+}(11.6 \%),{ }^{83} \mathrm{KrH}^{+}(11.5 \%),{ }^{84} \mathrm{KrH}^{+}(57 \%),{ }^{86} \mathrm{KrH}^{+}$(17.3\%). The proton affinity value of $\mathrm{Kr}$ is very close to the $\mathrm{H}_{2}$ value and we recorded spectra with the best $\mathrm{S} / \mathrm{N}$ for a relative pressure ratio $\mathrm{P}_{\mathrm{Kr}} / \mathrm{P}_{\mathrm{H}_{2}}=6$ for a total pressure estimated to 0.1 mbar.

\subsubsection{Ground state pure rotation transitions in the FIR}

The pure rotation spectrum of $\mathrm{KrH}^{+}$in its GS was recorded using the maximum resolution of the spectrometer $\left(\approx 0.001 \mathrm{~cm}^{-1}\right)$. An overview of the far-IR spectrum obtained by averaging 32 interferograms is displayed in figure 1 In these conditions and despite relatively intense absorption lines, the $\mathrm{S} / \mathrm{N}$ of the $\mathrm{KrH}^{+}$transitions remains relatively low (less than 10 for 
the most intense lines). This is due to the limited number of co-added interferograms and some sputtering of the cathode which increased the noise in the low frequency region. Such limited S/N is also observed in the spectra of $\mathrm{XeH}^{+}$and $\mathrm{ArH}^{+}$(see Figs. 3 and 5 for the same reasons. In addition to the $\mathrm{KrH}^{+}$absorption lines, numerous intense lines are present on the spectrum of Fig. 1 1 with negative absorbances. They correspond to pure rotation transitions of residual water more abundant in the reference spectrum than during the recording of $\mathrm{KrH}^{+}$spectrum. Moreover, an intense noise located around $200 \mathrm{~cm}^{-1}$ can be identified on the spectrum as well as on the spectra of $\mathrm{XeH}^{+}$and $\mathrm{ArH}^{+}$. It is due to saturated absorption in this region from a Teflon film installed in the optical path.

The broad spectral range covered by the FTIR instrument led to the assignment of J values in the range $4 \leq \mathrm{J} \leq 17$ for the main isotopologue $\left({ }^{84} \mathrm{KrH}^{+}\right)$and $5 \leq \mathrm{J} \leq 14$ for the minor isotopologues ${ }^{82} \mathrm{KrH}^{+},{ }^{83} \mathrm{KrH}^{+}$, and ${ }^{86} \mathrm{KrH}^{+}$. The presence of four isotopologues of $\mathrm{KrH}^{+}$in natural abundance in our spectrum is shown on Fig. 2. In comparison with the literature dataset, the transitions observed for ${ }^{82} \mathrm{KrH}^{+},{ }^{84} \mathrm{KrH}^{+}$and ${ }^{86} \mathrm{KrH}^{+}$extend to high frequency the data reported in Refs. [15, 19, 20] which are limited to $J=6$. Pure rotation transitions of ${ }^{83} \mathrm{KrH}^{+}$are reported for the first time in the present study.

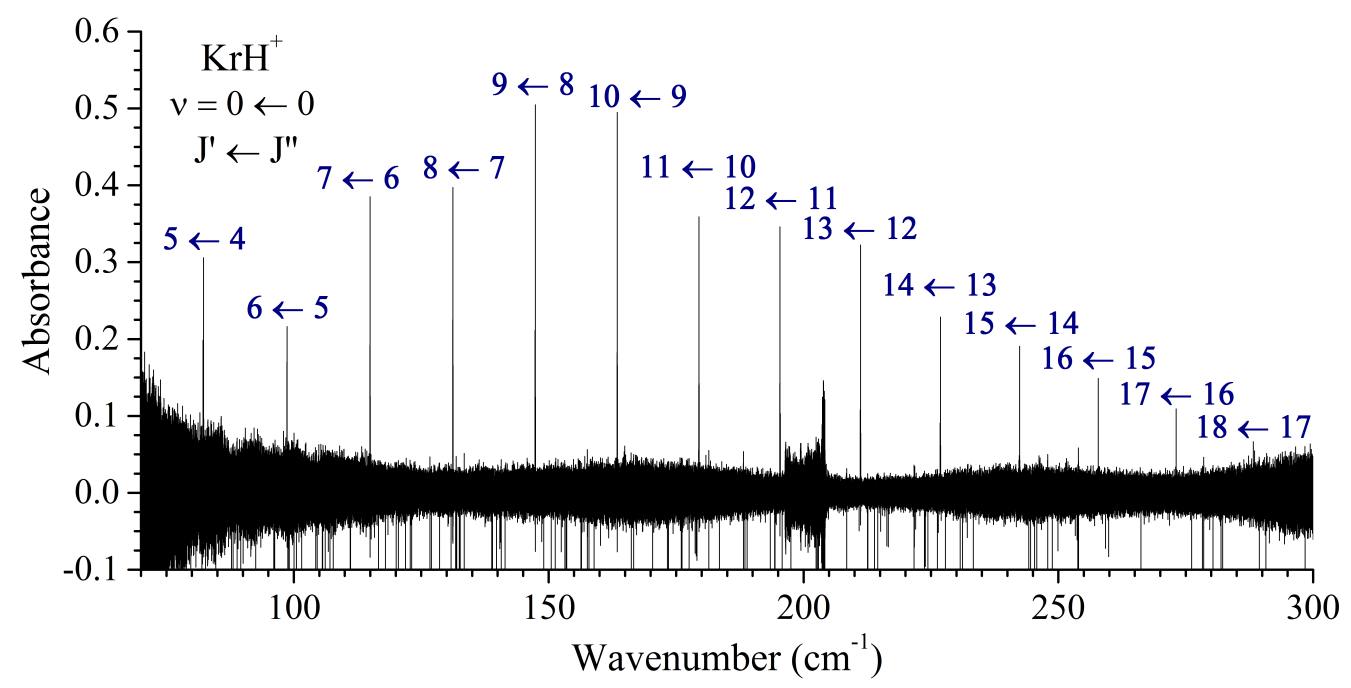

Figure 1: Pure rotation spectrum of $\mathrm{KrH}^{+}$recorded up to $300 \mathrm{~cm}^{-1}$. The numerous negative transitions are due to water impurity that absorbs in the spectral range.

\subsubsection{Rotation-vibration transitions of the $v=1 \leftarrow 0$ band in the mid-IR}

In the 2000-2700 $\mathrm{cm}^{-1}$, the $v=1 \leftarrow 0$ fundamental band of $\mathrm{KrH}^{+}$has been recorded at a resolution of $0.008 \mathrm{~cm}^{-1}$. A total of 40 scans were co-added to obtained a $\mathrm{S} / \mathrm{N}$ of about 10 


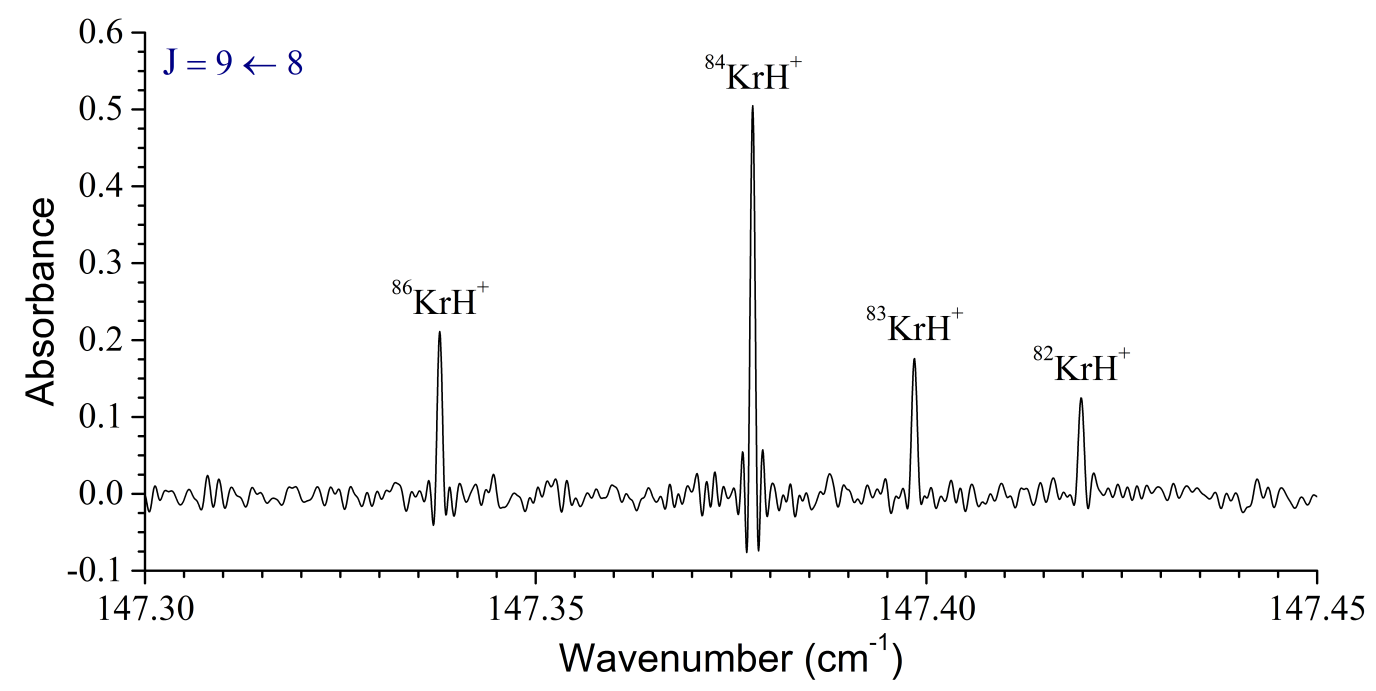

Figure 2: Portion of the far-IR absorption spectrum of $\mathrm{KrH}^{+}$around the $J=9 \leftarrow 8$ pure rotation transition exhibiting transitions of the four isotopologues of $\mathrm{KrH}^{+}$present in natural abundance in our absorption cell.

for the intense lines. In the $P$ and $R$ branches, transitions involving $J$ values up to 13 were assigned for ${ }^{84} \mathrm{KrH}^{+}$and as observed in the far-IR, several transitions were also identified for the minor species ${ }^{82} \mathrm{KrH}^{+},{ }^{83} \mathrm{KrH}^{+}$, and ${ }^{86} \mathrm{KrH}^{+}$. These data involving relatively low values of the quantum number $J$ are complementary with the work of Johns [8] realized by emission spectroscopy for which these low $J$ values were missing.

\subsubsection{Analysis}

We present the results of a combined fit including the dataset available from the literature for $\mathrm{KrH}^{+}[8,15,19,20]$ and the data reported our present study. A total of 407 transitions have been fitted using the two models described in section 2.3 The list of frequencies for $\mathrm{KrH}^{+}$measured in our work is given in table 4 and the complete linelist used in the fit is provided in the supplementary information.

The results of the fit using a standard Hamiltonian to model transitions of diatomic molecules is reported in Table 5. A total of 44 spectroscopic parameters, including the effective rotational constant $\mathrm{B}_{v}$ and the centrifugal distortion constants $\mathrm{D}_{v}$ and $\mathrm{H}_{v}$, was necessary to reproduce the data to their experimental uncertainties.

The same experimental dataset was fitted using the Dunham Hamiltonian formulation in dParFit, 12 parameters were necessary to reproduce the dataset to the experimental accuracies. The fit is presented in table 6 and compared to previous results from the 
literature. A general improvement of all the parameters can be observed in comparison with previous results. In particular, we can notice that the accuracy on $U_{0,1}$ has been improved by one order of magnitude. We also added to table 6 the calculated Dunham parameters from Ferrante et al. [41]. In Ref. [41], the comparison between experimental and calculated values was limited to 4 parameters, namely $\mathrm{U}_{1,0}, \mathrm{U}_{2,0}, \mathrm{U}_{0,1}$ and $\mathrm{U}_{1,1}$ showing very good agreement between observed and calculated values. One can notice in table 6 that such agreement is still good for the higher order terms fitted in our work. However, one of the higher order calculated parameter, $\mathrm{U}_{0,4}$, seems to be slightly overestimated in comparison with its experimental value. In addition to the set of $U_{(l, m)}$ parameters reported in table 6. we provide in supplementary material the set of $Y_{(l, m)}$ parameters fitted for each isotopologues.

\subsubsection{Bond length of $\mathrm{KrH}^{+}$}

Using the value of $\mathrm{U}_{0,1}$ and Eq. 9 , the Born-Oppenheimer bond distance of $\mathrm{KrH}^{+}$was derived. Its value, $r_{e}=1.421191108(55) \AA$, is in good agreement with the bond length obtained by Linnartz et al. [19] of $r_{e}=1.4211904(5) \AA$. The accuracy on this bond distance was improved by one order of magnitude which we assume is mostly due to the inclusion into the fit of the new set of transitions assigned for ${ }^{83} \mathrm{KrH}^{+}$.

\subsection{Spectroscopy of $\mathrm{XeH}^{+}$}

$\mathrm{XeH}^{+}$is a diatomic molecule with a calculated permanent dipole moment of $1.551 \mathrm{D}$ [42]. The bond length at the equilibrium geometry was determined by Peterson et al. [16] and is equal to $r_{e}^{B O}=1.6028114(13) \AA$. As the krypton atom, xenon possesses multiple stable isotopes (9 in total): ${ }^{124} \mathrm{Xe}(0.1 \%),{ }^{126} \mathrm{Xe}(0.1 \%),{ }^{128} \mathrm{Xe}(1.9 \%),{ }^{129} \mathrm{Xe}(26.4 \%),{ }^{130} \mathrm{Xe}(4.1 \%)$, ${ }^{131} \mathrm{Xe}(21.2 \%),{ }^{132} \mathrm{Xe}(26.9 \%),{ }^{134} \mathrm{Xe}(10.4 \%)$ and ${ }^{136} \mathrm{Xe}(8.9 \%)$. To synthesize $\mathrm{XeH}^{+}$species, we mixed $\mathrm{Xe}$ and $\mathrm{H}_{2}$ in the discharge as described in previous sections. Because the proton affinity of Xe is much larger than $\mathrm{H}_{2}$ proton affinity, we could inject a lot more $\mathrm{H}_{2}$ than Xe in the cell to favour the production of $\mathrm{XeH}^{+}$. The best ratio was found in our experiment when $\mathrm{P}_{\mathrm{Xe}} / \mathrm{P}_{\mathrm{H}_{2}}=1 / 16$. On the other hand, because of the condensation of $\mathrm{Xe}$, we could not cool down the cathode to liquid nitrogen temperature and the higher temperature of the cathode (about $193 \mathrm{~K}$ ) was a limiting factor in the production of $\mathrm{XeH}^{+}$in our set-up. 


\begin{tabular}{|c|c|c|c|c|c|}
\hline \multicolumn{6}{|c|}{ Pure rotation } \\
\hline$J^{\prime}$ & $J^{\prime \prime}$ & ${ }^{86} \mathrm{KrH}^{+}$ & ${ }^{84} \mathrm{KrH}^{+}$ & ${ }^{83} \mathrm{KrH}^{+}$ & ${ }^{82} \mathrm{KrH}^{+}$ \\
\hline 5 & 4 & & $82.29605(3)$ & & \\
\hline 6 & 5 & $98.62930(7)$ & $98.65621(3)$ & 98.66988(7) & 98.68443(7) \\
\hline 7 & 6 & $114.93114(7)$ & $114.97867(3)$ & $114.98047(7)$ & $114.99538(7)$ \\
\hline 8 & 7 & 131.17021(7) & $131.20596(3)$ & $131.22443(7)$ & 131.24341(7) \\
\hline 9 & 8 & $147.33766(7)$ & $147.37768(3)$ & $147.39838(7)$ & 147.41973(7) \\
\hline 10 & 9 & $163.42453(7)$ & $163.46885(3)$ & $163.49181(7)$ & $163.51540(7)$ \\
\hline 11 & 10 & $179.42215(7)$ & 179.47077(3) & 179.49587(7) & 179.52174(7) \\
\hline 12 & 11 & 195.32174(7) & $195.37456(3)$ & 195.40183(7) & 195.42991(7) \\
\hline 13 & 12 & $211.11460(7)$ & 211.17158(3) & $211.20096(7)$ & 211.23126(7) \\
\hline 14 & 13 & $226.79220(7)$ & $226.85316(3)$ & $226.88460(7)$ & $226.91716(7)$ \\
\hline 15 & 14 & $242.34596(7)$ & 242.41084(3) & $242.44465(7)$ & \\
\hline 16 & 15 & & $257.83602(3)$ & & \\
\hline 17 & 16 & & 273.12024(3) & & \\
\hline 18 & 17 & & $288.25511(3)$ & & \\
\hline \multicolumn{6}{|c|}{ Rotation-vibration } \\
\hline$J^{\prime}$ & $J^{\prime \prime}$ & ${ }^{86} \mathrm{KrH}^{+}$ & ${ }^{84} \mathrm{KrH}^{+}$ & ${ }^{83} \mathrm{KrH}^{+}$ & ${ }^{82} \mathrm{KrH}^{+}$ \\
\hline 13 & 14 & & $2122.9601(3)$ & & \\
\hline 12 & 13 & & 2145.4503(3) & & \\
\hline 11 & 12 & 2167.2863(6) & $2167.5376(3)$ & & \\
\hline 10 & 11 & 2188.9553(6) & $2189.2116(3)$ & 2189.3438(6) & \\
\hline 9 & 10 & $2210.1996(6)$ & $2210.4629(3)$ & $2210.6003(6)$ & 2210.7373(6) \\
\hline 8 & 9 & $2231.0107(6)$ & $2231.2813(3)$ & $2231.4206(6)$ & $2231.5629(6)$ \\
\hline 7 & 8 & $2251.3807(6)$ & $2251.6568(3)$ & $2251.7999(6)$ & $2251.9442(6)$ \\
\hline 6 & 7 & 2271.2985(6) & $2271.5807(3)$ & 2271.7255(6) & $2271.8758(6)$ \\
\hline 5 & 6 & $2290.7554(6)$ & $2291.0430(3)$ & 2291.1908(6) & 2291.3447(6) \\
\hline 4 & 5 & $2309.7410(6)$ & $2310.0338(3)$ & $2310.1854(6)$ & $2310.3405(6)$ \\
\hline 3 & 4 & $2328.2464(6)$ & $2328.5443(3)$ & $2328.6990(6)$ & $2328.8561(6)$ \\
\hline 2 & 3 & $2346.2614(6)$ & $2346.5648(3)$ & $2346.7218(6)$ & $2346.8832(6)$ \\
\hline 1 & 2 & 2363.7782(6) & $2364.0860(3)$ & $2364.2455(6)$ & $2364.4090(6)$ \\
\hline 0 & 1 & 2380.7863(6) & 2381.0991(3) & $2381.2611(6)$ & $2381.4264(6)$ \\
\hline 1 & 0 & 2413.2411(6) & 2413.5627(3) & 2413.7281(6) & 2413.8995(6) \\
\hline 2 & 1 & $2428.6694(6)$ & $2428.9959(3)$ & $2429.1645(6)$ & $2429.3377(6)$ \\
\hline 3 & 2 & $2443.5549(6)$ & $2443.8849(3)$ & $2444.0557(6)$ & $2444.2315(6)$ \\
\hline 4 & 3 & $2457.8873(6)$ & $2458.2209(3)$ & $2458.3936(6)$ & $2458.5702(6)$ \\
\hline 5 & 4 & $2471.6579(6)$ & 2471.9951(3) & $2472.1691(6)$ & $2472.3489(6)$ \\
\hline 6 & 5 & 2484.8598(6) & 2485.1994(3) & $2485.3748(6)$ & $2485.5547(6)$ \\
\hline 7 & 6 & 2497.4822(6) & 2497.8253(3) & $2498.0027(6)$ & 2498.1843(6) \\
\hline 8 & 7 & 2509.5190(6) & $2509.8645(3)$ & $2510.0421(6)$ & $2510.2264(6)$ \\
\hline 9 & 8 & $2520.9615(6)$ & 2521.3093(3) & $2521.4872(6)$ & $2521.6732(6)$ \\
\hline 10 & 9 & $2531.8007(6)$ & 2532.1511(3) & $2532.3295(6)$ & $2532.5191(6)$ \\
\hline 11 & 10 & $2542.0316(6)$ & $2542.3826(3)$ & $2542.5641(6)$ & $2542.7498(6)$ \\
\hline 12 & 11 & & 2551.9964(3) & & \\
\hline 13 & 12 & & $2560.9841(3)$ & & \\
\hline 14 & 13 & & 2569.3371(3) & & \\
\hline
\end{tabular}

Table 4: Experimental linelist of $\mathrm{KrH}^{+}$assigned from our far-IR and mid-IR spectra (all values are in $\mathrm{cm}^{-1}$ ). Uncertainties are given in parenthesis in units of the last digit of the measured frequency. 


\begin{tabular}{|c|c|c|c|c|}
\hline & ${ }^{82} \mathrm{KrH}^{+}$ & ${ }^{83} \mathrm{KrH}^{+}$ & ${ }^{84} \mathrm{KrH}^{+}$ & ${ }^{86} \mathrm{KrH}^{+}$ \\
\hline Parameters & \multicolumn{4}{|c|}{ Ground State } \\
\hline$B(\mathrm{MHz})$ & $247351.1353(63)$ & $247314.93(21)$ & $247280.0892(67)$ & 247212.399(10) \\
\hline$D(\mathrm{kHz})$ & 11270.13(12) & 11265.7(16) & 11262.73(10) & 11257.61(19) \\
\hline$H(\mathrm{~Hz})$ & 208.95(80) & 206.4(38) & 205.28(25) & 209.09(73) \\
\hline \multirow[t]{2}{*}{ No. lines } & 13 & 10 & 18 & 14 \\
\hline & \multicolumn{4}{|c|}{$v=1$} \\
\hline$E(\mathrm{MHz})$ & $71888045.5(70)$ & $71882991.8(70)$ & $71878070.3(31)$ & $71868545.2(66)$ \\
\hline$B(\mathrm{MHz})$ & $239453.85(21)$ & 239419.45(28) & $239386.494(55)$ & 239322.17(15) \\
\hline$D(\mathrm{kHz})$ & 11140.5(12) & 11136.6(19) & $11135.09(22)$ & 11130.64(69) \\
\hline$H(\mathrm{~Hz})$ & 197.9(19) & 197.1(34) & $197.60(26)$ & 201.28(89) \\
\hline \multirow[t]{2}{*}{ No. lines } & 42 & 53 & 54 & 47 \\
\hline & \multicolumn{4}{|c|}{$v=2$} \\
\hline$\overline{E(\mathrm{MHz})}$ & 140865412.(71) & 140855858.(211) & 140846365.(13) & 140828159.(47) \\
\hline$B(\mathrm{MHz})$ & 231673.3(16) & 231638.8(53) & $231606.85(25)$ & 231544.7(10) \\
\hline$D(\mathrm{kHz})$ & 11030.1(95) & 11012.(36) & 11008.5(11) & 10997.8(59) \\
\hline$H(\mathrm{~Hz})$ & 219.(15) & 188.(70) & 191.7(13) & 183.9(93) \\
\hline No. of lines & 23 & 24 & 36 & 25 \\
\hline
\end{tabular}

Table 5: Molecular parameters for the ground, $v=1$ and $v=2$ states of $\mathrm{KrH}^{+}$isotopologues. Numbers in parentheses are $1 \sigma$ uncertainties in units of the last digit.

\begin{tabular}{lrrrr}
\hline \hline Parameters & This work & Odashima et al. [20] & Johns [8] & Ferrante et al. [41] \\
\hline \hline$U_{1,0}$ & $2489.49722(23)$ & {$[2489.49809]^{*}$} & $2489.49809(34)$ & 2545.8 \\
$U_{2,0}$ & $-48.32927(11)$ & {$[-48.32899]^{*}$} & $-48.32899(13)$ & -45.6 \\
$U_{0,1}$ & $8.34625277(65)$ & $8.3462516(53)$ & $8.346842(10)$ & 8.431 \\
$U_{1,1}$ & $-0.2654275(14)$ & {$[-0.2654179]^{*}$} & $-0.2654179(25)$ & -0.275 \\
$U_{2,1}$ & $0.00188265(55)$ & {$[0.00188098]^{*}$} & $0.00188098(77)$ & 0.00170 \\
$U_{0,2}\left(.10^{-3}\right)$ & $-0.3745040(25)$ & $-0.3745597(56)$ & $-0.374785(57)$ & -0.370 \\
$U_{1,2}\left(.10^{-6}\right)$ & $4.0696(27)$ & {$[4.0534]^{*}$} & $4.0534(50)$ & 7.67 \\
$U_{0,3}\left(.10^{-9}\right)$ & $7.1835(95)$ & $7.4518(90)$ & $7.53(12)$ & 6.66 \\
$U_{0,4}\left(.10^{-12}\right)$ & $-0.855(15)$ & {$[-1.054]^{*}$} & $-1.054(74)$ & -29.7 \\
$\Delta_{0,1}^{\mathrm{Kr}}$ & $0.941(32)$ & $0.972(94)$ & - & - \\
$\Delta_{0,1}^{\mathrm{H}}$ & $0.116365(89)$ & $0.11533(18)$ & - & - \\
$\Delta_{0,2}^{\mathrm{H}}$ & $0.872(12)$ & $0.657(49)$ & - & - \\
\hline Nb. Trans. & 407 & & & \\
Reduced RMS & 0.8210 & & & \\
\hline * Parameter kept fixed to the value determined by Johns 8$]$ & & & \\
\hline
\end{tabular}

Table 6: Results of the combined fit of pure rotation and rotation-vibration transitions of $\mathrm{KrH}^{+}$using a Dunham Hamiltonian. Parameters $U_{(l, m)}$ are expressed in $\mathrm{cm}^{-1} \cdot \mathrm{u}^{(m+l / 2)}$, parameters $\Delta_{l, m}$ are dimensionless. Numbers in parentheses are $2 \sigma$ uncertainties in units of the last digit. 


\subsubsection{Ground state pure rotation transitions in the FIR}

In the far-IR range, the $\mathrm{XeH}^{+}$transitions are significantly weaker than the ones observed for $\mathrm{KrH}^{+}$, a likely reflection of both the smaller permanent dipole moment of $\mathrm{XeH}^{+}$as well as the cathode' higher temperature required when dealing with Xe. A longer acquisition time was thus required to record the pure rotation spectrum of $\mathrm{XeH}^{+}$(average of 52 interferograms) at the maximum resolution available with our spectrometer $\left(0.001 \mathrm{~cm}^{-1}\right)$ of the FTIR. Due to the relatively low $\mathrm{S} / \mathrm{N}$ ratio (about 2!), only three isotopologues could be detected. A total of 9 transitions (7 of them are observed for the first time) were assigned with $J^{\prime \prime}=9-11$ for ${ }^{129} \mathrm{XeH}^{+},{ }^{131} \mathrm{XeH}^{+},{ }^{132} \mathrm{XeH}^{+}$. Our results slightly extend toward high frequencies the pure rotation transitions reported in the literature [16, 17, 21] concerning these isotopologues for which transitions involving $J$ from $J^{\prime \prime}=0$ to $J^{\prime \prime}=10$ were already measured.

\subsubsection{Rotation-vibration transitions of the $v=1 \leftarrow 0$ band in the mid-IR}

In the mid-IR, the $v=1 \leftarrow 0$ fundamental band of $\mathrm{XeH}^{+}$was recorded with a resolution of $0.0025 \mathrm{~cm}^{-1}$. The averaged spectrum (42 co-added scans) is displayed on Fig. 3 The relatively good $\mathrm{S} / \mathrm{N}$ in the mid-IR in comparison with our far-IR spectrum led to the detection of 6 of the 9 stable isotopologues of $\mathrm{XeH}^{+}:{ }^{129} \mathrm{XeH}^{+},{ }^{130} \mathrm{XeH}^{+},{ }^{131} \mathrm{XeH}^{+},{ }^{132} \mathrm{XeH}^{+},{ }^{134} \mathrm{XeH}^{+}$, ${ }^{136} \mathrm{XeH}^{+}$. Transitions with $J$ values up to 13 and 12 were assigned in the $P$ and $R$ branches, respectively. A total of 130 transitions have been assigned considering all the isotopologues, including 49 new transitions of the minor species ${ }^{130} \mathrm{XeH}^{+},{ }^{134} \mathrm{XeH}^{+}$and ${ }^{136} \mathrm{XeH}^{+}$. To our knowledge, no rovibrational data on these three isotopologues were reported in the literature before. In addition, the frequency accuracy of the measured transitions of ${ }^{129} \mathrm{XeH}^{+}$, ${ }^{131} \mathrm{XeH}^{+},{ }^{132} \mathrm{XeH}^{+}$have been improved by a factor 8 in comparison with Rogers et al. [9].

\subsubsection{Analysis}

The list of frequencies for $\mathrm{XeH}^{+}$measured in our work is given in table 7. As for $\mathrm{KrH}^{+}$, we performed a combined fit of the most complete data set available. The linelist is composed of 325 transitions and includes data from Refs. [9, 16, 17, 21] together with our far-IR and mid-IR measurements. Again, the two models presented earlier were used to fit the data. Table 8 reports the results of the fit using standard Hamiltonian in which 48 parameters have been adjusted to reproduce the measurements to their experimental accuracies while Table 9 reports the results of the multi-isopologues fit using the Dunham Hamiltonian in which 11 parameters were included. The parameters determined in our study agrees very well 


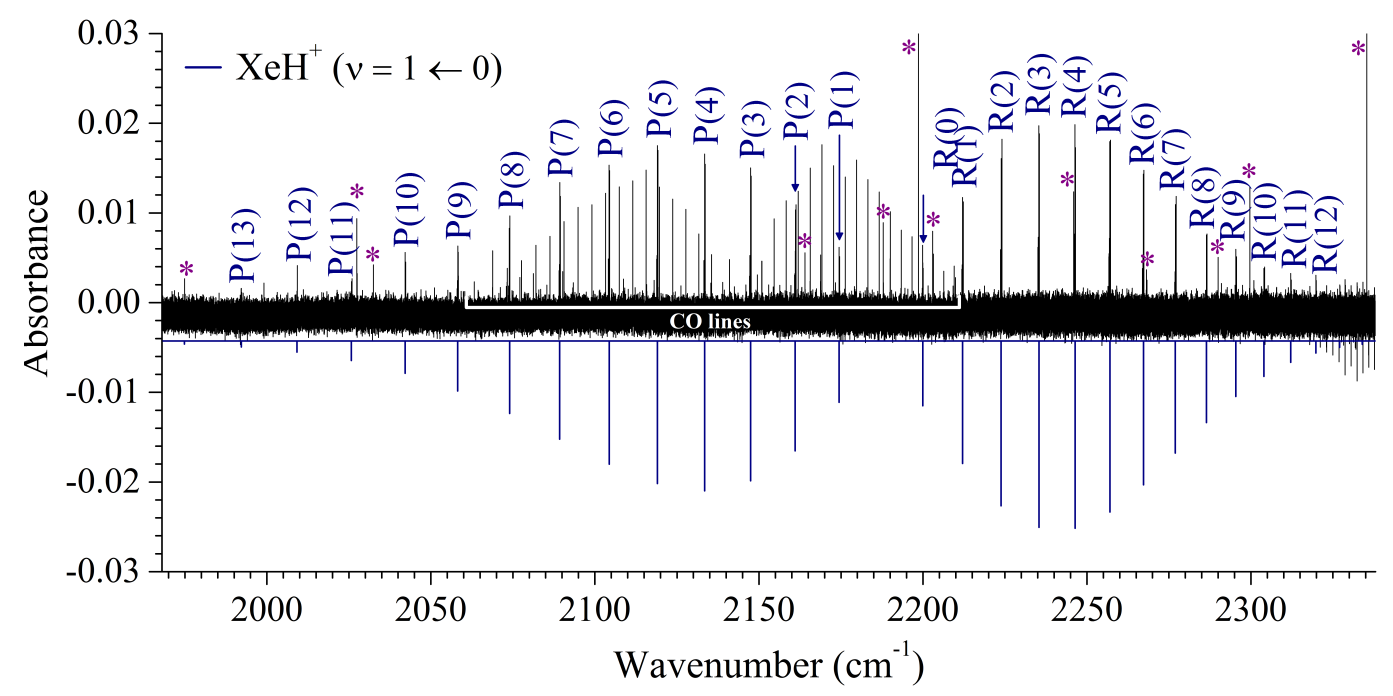

Figure 3: The upper trace of the figure represents the absorption spectrum of the fundamental band of $\mathrm{XeH}^{+}$centered around $2200 \mathrm{~cm}^{-1}$. Satellite transitions from CO present as impurity as well as relatively intense Rydberg transitions of xenon (indicated by an asterisk) are detected on the spectrum. The lower trace represents a simulation of the band using our fitted set of parameters.

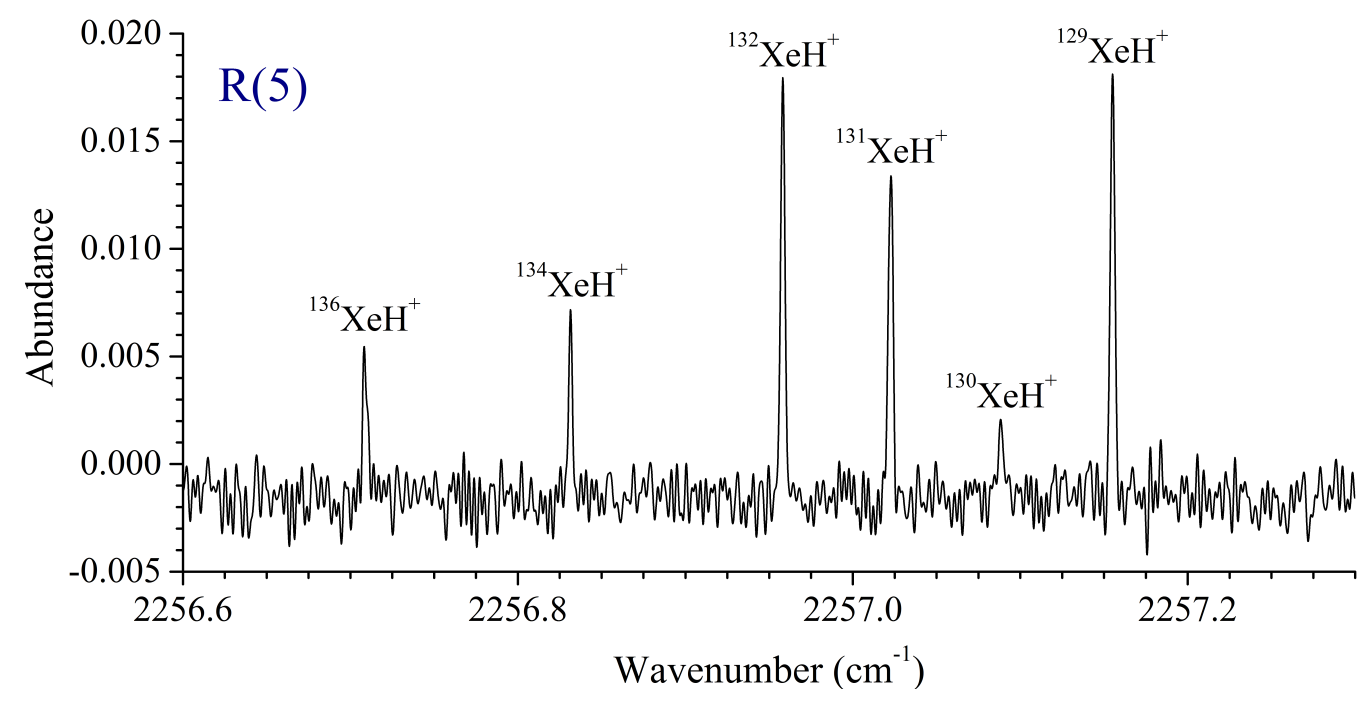

Figure 4: Cluster of the $R(5)$ transitions of the fundamental band of $\mathrm{XeH}^{+} .6$ lines assigned to the most abundant isotopologues of $\mathrm{XeH}^{+}$are observed on this spectrum. 


\begin{tabular}{|c|c|c|c|c|c|c|c|}
\hline \multicolumn{8}{|c|}{ Pure rotation } \\
\hline$J^{\prime}$ & $J^{\prime \prime}$ & ${ }^{136} \mathrm{XeH}^{+}$ & ${ }^{134} \mathrm{XeH}^{+}$ & ${ }^{132} \mathrm{XeH}^{+}$ & ${ }^{131} \mathrm{XeH}^{+}$ & ${ }^{130} \mathrm{XeH}^{+}$ & ${ }^{129} \mathrm{XeH}^{+}$ \\
\hline 10 & 9 & & & $128.4768(5)$ & 128.4844(5) & & 128.4993(5) \\
\hline 11 & 10 & & & $141.1236(5)$ & $141.1317(5)$ & & 141.1481(5) \\
\hline 12 & 11 & & & $153.7129(5)$ & $153.7215(5)$ & & $153.7397(5)$ \\
\hline \multicolumn{8}{|c|}{ Rotation-vibration } \\
\hline$J^{\prime}$ & $J^{\prime \prime}$ & ${ }^{136} \mathrm{XeH}^{+}$ & ${ }^{134} \mathrm{XeH}^{+}$ & ${ }^{132} \mathrm{XeH}^{+}$ & ${ }^{131} \mathrm{XeH}^{+}$ & ${ }^{130} \mathrm{XeH}^{+}$ & ${ }^{129} \mathrm{XeH}^{+}$ \\
\hline 13 & 14 & & & 1974.8926(3) & & & 1975.0374(3) \\
\hline 12 & 13 & & & 1992.1663(3) & & & 1992.3158(3) \\
\hline 11 & 12 & & & $2009.1390(3)$ & 2009.1889(3) & & 2009.2916(3) \\
\hline 10 & 11 & 2025.6072(5) & 2025.7049(5) & $2025.8050(3)$ & $2025.8558(3)$ & & 2025.9605(3) \\
\hline 9 & 10 & & & 2042.1581(3) & $2042.2103(3)$ & & 2042.3172(3) \\
\hline 8 & 9 & 2057.9891(5) & 2058.0898(5) & 2058.1943(3) & 2058.2471(3) & & 2058.3557(3) \\
\hline 7 & 8 & 2073.6976(5) & 2073.8006(5) & 2073.9064(3) & 2073.9606(3) & & 2074.0711(3) \\
\hline 6 & 7 & 2089.0779(5) & 2089.1823(5) & 2089.2901(3) & 2089.3453(3) & & 2089.4577(3) \\
\hline 5 & 6 & $2104.1240(5)$ & $2104.2306(5)$ & $2104.3400(3)$ & $2104.3959(3)$ & & 2104.5105(3) \\
\hline 4 & 5 & 2118.8311(5) & 2118.9387(5) & $2119.0505(3)$ & 2119.1074(3) & 2119.1651(7) & 2119.2238(3) \\
\hline 3 & 4 & 2133.1934(5) & 2133.3035(5) & 2133.4164(3) & $2133.4738(3)$ & $2133.5334(7)$ & 2133.5923(3) \\
\hline 2 & 3 & 2147.2066(5) & 2147.3178(5) & $2147.4323(3)$ & $2147.4908(3)$ & & 2147.6107(3) \\
\hline 1 & 2 & $2160.8640(5)$ & 2160.9765(5) & $2161.0926(3)$ & 2161.1518(3) & & 2161.2739(3) \\
\hline 0 & 1 & 2174.1596(5) & $2174.2739(5)$ & $2174.3927(3)$ & $2174.4526(3)$ & & $2174.5760(3)$ \\
\hline 1 & 0 & $2199.6526(5)$ & 2199.7696(5) & $2199.8898(3)$ & 2199.9524(3) & & $2200.0778(3)$ \\
\hline 2 & 1 & 2211.8361(5) & 2211.9541(5) & $2212.0763(3)$ & $2212.1390(3)$ & & $2212.2658(3)$ \\
\hline 3 & 2 & $2223.6389(5)$ & 2223.7585(5) & $2223.8814(3)$ & $2223.9443(3)$ & $2224.0085(7)$ & 2224.0732(3) \\
\hline 4 & 3 & $2235.0545(5)$ & 2235.1755(5) & $2235.2997(3)$ & $2235.3633(3)$ & $2235.4268(7)$ & $2235.4934(3)$ \\
\hline 5 & 4 & $2246.0792(5)$ & $2246.2010(5)$ & $2246.3263(3)$ & 2246.3904(3) & $2246.4558(7)$ & $2246.5215(3)$ \\
\hline 6 & 5 & $2256.7063(5)$ & $2256.8296(5)$ & 2256.9563(3) & $2257.0209(3)$ & $2257.0864(7)$ & 2257.1533(3) \\
\hline 7 & 6 & $2266.9328(5)$ & $2267.0563(5)$ & $2267.1839(3)$ & $2267.2490(3)$ & $2267.3147(7)$ & $2267.3825(3)$ \\
\hline 8 & 7 & $2276.7515(5)$ & $2276.8765(5)$ & $2277.0048(3)$ & $2277.0706(3)$ & 2277.1373(7) & $2277.2048(3)$ \\
\hline 9 & 8 & $2286.1579(5)$ & $2286.2847(5)$ & $2286.4139(3)$ & $2286.4803(3)$ & $2286.5465(7)$ & $2286.6150(3)$ \\
\hline 10 & 9 & 2295.1488(5) & $2295.2756(5)$ & 2295.4058(3) & $2295.4719(3)$ & & 2295.6084(3) \\
\hline 11 & 10 & & & $2303.9759(3)$ & & & 2304.1788(3) \\
\hline 12 & 11 & & & $2312.1202(3)$ & 2312.1863(3) & & 2312.3236(3) \\
\hline 13 & 12 & & & 2319.8321(3) & 2319.8994(3) & & 2320.0364(3) \\
\hline 14 & 13 & & & 2327.1078(3) & 2327.1753(3) & & 2327.3137(3) \\
\hline
\end{tabular}

Table 7: Experimental linelist of $\mathrm{XeH}^{+}$assigned in the far-IR and in the mid-IR spectra (the values are in $\mathrm{cm}^{-1}$ ). Uncertainties are given in parenthesis in units of the last digit of the measured frequency. 
with previous results. Our combined fit allows to improve slightly the accuracy of several parameters of the Dunham Hamiltonian. As example, the accuracy of $U_{1,0}$ is improved by a factor of 3 thanks to the new rotation-vibration transitions assigned in the mid-IR region. Note that for $\mathrm{XeH}^{+}$, the parameter $\Delta_{0,2}^{\mathrm{H}}$ has been added to the fit as well. The addition of this parameter improved the RMS by about $10 \%$ without decreasing the accuracy on the other parameters. As for $\mathrm{KrH}^{+}$, the calculated parameters from Ferrante et al. [41] are in excellent agreement with our experimental values. We also provide in supplementary material the set of $Y_{(l, m)}$ parameters fitted for each isotopologues of $\mathrm{XeH}^{+}$.

\begin{tabular}{|c|c|c|c|c|c|c|}
\hline & ${ }^{129} \mathrm{XeH}^{+}$ & ${ }^{130} \mathrm{XeH}^{+}$ & ${ }^{131} \mathrm{XeH}^{+}$ & ${ }^{132} \mathrm{XeH}^{+}$ & ${ }^{134} \mathrm{XeH}^{+}$ & ${ }^{136} \mathrm{XeH}^{+}$ \\
\hline Parameters & \multicolumn{6}{|c|}{ Ground State } \\
\hline$B(\mathrm{MHz})$ & 193923.5712(30) & 193912.16(10) & 193900.7799(15) & $193889.6398(12)$ & 193867.8302(21) & $193846.6617(21)$ \\
\hline$D(\mathrm{kHz})$ & $6550.641(96)$ & 6568.(50) & 6549.390(79) & $6548.762(75)$ & $6547.20(36)$ & $6546.48(36)$ \\
\hline \multirow[t]{2}{*}{ No. lines } & 11 & 2 & 9 & 10 & 5 & 5 \\
\hline & \multicolumn{6}{|c|}{$v=1$} \\
\hline$E(\mathrm{MHz})$ & $65579968.5(50)$ & 65578090.(38) & $65576230.1(51)$ & $65574409.0(50)$ & $65570836.7(88)$ & $65567369.5(88)$ \\
\hline$D(\mathrm{kHz})$ & $6518.2(21)$ & 6522.(46) & $6518.9(24)$ & $6511.9(22)$ & 6501.6(47) & 6502.6(47) \\
\hline$H(\mathrm{~Hz})$ & $75.7(60)$ & - & $85.7(70)$ & $64.0(62)$ & - & - \\
\hline \multirow[t]{2}{*}{ No. lines } & 34 & 9 & 34 & 34 & 20 & 20 \\
\hline & \multicolumn{6}{|c|}{$v=2$} \\
\hline$E(\mathrm{MHz})$ & 128682024.(32) & - & 128674853.(32) & $128671236 .(40)$ & - & - \\
\hline$B(\mathrm{MHz})$ & $182826.09(84)$ & - & $182805.83(84)$ & 182799.6(19) & - & - \\
\hline
\end{tabular}

Table 8: Molecular parameters for the ground, $v=1$, and $v=2$ states of $\mathrm{XeH}^{+}$isotopologues. Numbers in parentheses are $1 \sigma$ uncertainties in units of the last digit.

\begin{tabular}{|c|c|c|c|c|c|c|}
\hline Parameters & This work (1) & This work (2) & Ting and Amano [17] & Ohtaki et al. [21] & Rogers et al. [9] & Ferrante et al. [41] \\
\hline$U_{1,0}$ & $2270.18077(43)$ & $2270.18053(49)$ & {$\left[\begin{array}{l}2270.1799]^{*} \\
\end{array}\right.$} & {$\left[\right.$ [2270.1799]* $^{*}$} & 2270.1799(11) & 2286.8 \\
\hline$U_{2,0}$ & $-41.32853(21)$ & $-41.32866(24)$ & {$[-41.32830]^{*}$} & {$[-41.32830]^{*}$} & $-41.32830(34)$ & -36.6 \\
\hline$U_{0,1}$ & $6.5619318(20)$ & $6.5619286(21)$ & $6.5619256(70)$ & $6.5619216(22)$ & 6.561914(50) & 6.601 \\
\hline$U_{1,1}$ & $-0.1867421(50)$ & $-0.1867243(55)$ & $-0.186689(15)$ & $-0.1866875(87)$ & $-0.186739(14)$ & -0.188 \\
\hline$U_{2,1}$ & $0.0005660(24)$ & $0.0005689(26)$ & $0.0005608(56)$ & $0.0005606(32)$ & $0.0005654(35)$ & 0.00096 \\
\hline$U_{0,2}\left(.10^{-3}\right)$ & $-0.2190213(49)$ & $-0.2189960(23)$ & $-0.2189883(42)$ & $-0.2189868(25)$ & $-0.21915(34)$ & -0.220 \\
\hline$U_{1,2}\left(.10^{-6}\right)$ & $1.1018(85)$ & $0.9437(38)$ & $0.9313(77)$ & $0.9266(47)$ & $1.108(37)$ & 4.18 \\
\hline$m U_{0,3}\left(.10^{-9}\right)$ & $2.5451(65)$ & $2.5699(70)$ & $2.549(13)$ & $2.5521(77)$ & $2.67(67)$ & 2.94 \\
\hline$\Delta_{01}^{\mathrm{Xe}}$ & $0.526(16)$ & $0.511(18)$ & $0.359(37)$ & $0.483(45)$ & - & - \\
\hline$\Delta_{01}^{0,1}$ & $-0.01469(25)$ & $-0.01639(27)$ & $-0.0874(86)$ & $-0.0150(30)$ & - & - \\
\hline$\Delta_{0,2}^{\mathrm{H}}$ & $0.435(22)$ & - & & - & - & - \\
\hline Nb. Trans & 325 & 325 & & & & \\
\hline Reduced RMS & 0.7984 & 0.9210 & & & & \\
\hline
\end{tabular}

Table 9: Results of the combined fit of pure rotation and rotation-vibration transitions of $\mathrm{XeH}^{+}$using a Dunham Hamiltonian. $U_{(l, m)}$ parameters are expressed in $\mathrm{cm}^{-1} \cdot \mathrm{u}^{(m+l / 2)}, \Delta_{l, m}$ are dimensionless. Numbers in parentheses are $2 \sigma$ uncertainties in units of the last digit. 


\subsubsection{Bond length of $\mathrm{XeH}^{+}$}

From the value of the experimental parameter $U_{0,1}$, the Born-Oppenheimer bond distance can be deduced using Eq.99 and we can derive $r_{e}=1.60281129(24) \AA$. This value is in good agreement with the value of 1.6028114(13) $\AA$ reported by Peterson et al. [16] and a slight improvement on the accuracy of this bond length can be noticed. As expected, the bond distance determined for $\mathrm{XeH}^{+}$is longer than for $\mathrm{KrH}^{+}\left(r_{e}=1.421191108(55) \AA\right)$ considering the size difference between $\mathrm{Xe}$ and $\mathrm{Kr}$ atoms.

\subsection{Spectroscopy of $\mathrm{ArH}^{+}$}

As for $\mathrm{KrH}^{+}$and $\mathrm{XeH}^{+}, \mathrm{ArH}^{+}$is a close-shell diatomic molecule with ground electronic state ${ }^{1} \Sigma^{+}$. The molecule has a relatively strong permanent dipole moment of about $3.0 \mathrm{D}$, which has been experimentally determined by Laughlin et al. [43]. In its equilibrium geometry, Laughlin et al. [22] determined a bond length of 1.280375(7) A. The argon atom possesses three stable isotopes $(A=36,38,40)$ whose natural abundances are significantly different on Earth and in space. The natural abundances on Earth of ${ }^{36} \mathrm{Ar},{ }^{38} \mathrm{Ar},{ }^{40} \mathrm{Ar}$ are respectively $0.337 \%, 0.063 \%$ and $99.600 \%$ whereas in the sun ${ }^{36} \mathrm{Ar}$ represents $84.6 \%$ of the total $\mathrm{Ar}$ abundances [44] and the isotopic ratio ${ }^{36} \mathrm{Ar} /{ }^{40} \mathrm{Ar}$ is about 8600 in giant planets [45].

As shown in table 1. numerous high quality data are already available in the literature. We present below the experimental results of our investigations although for this molecule our limited dataset did not influence sufficiently the parameters of the fit published by Bizzocchi et al. [13] to include a new table of parameters in the present notice. We thus refer the reader to this paper for the most updated set of parameter concerning this species.

\subsubsection{Ground state pure rotation transitions in the FIR}

A broadband overview of the GS pure rotation spectrum of $\mathrm{ArH}^{+}$is shown in Fig. 5 The spectrum consists of an averaging of 42 interferograms recorded at the maximum instrumental resolution of $0.001 \mathrm{~cm}^{-1}$ which represents an acquisition time of about 6 hours including the buffer periods necessary to cool down the cathode. As for $\mathrm{KrH}^{+}$, numerous intense water lines are present on the spectrum in addition to the $\mathrm{ArH}^{+}$absorption lines.

The wide spectral range covered by the FTIR spectrometer allowed us to observe a total of $10 R$-type transitions covering the range of $J^{\prime \prime}=3$ to $J^{\prime \prime}=12$. Due to the isotopic ratios of argon on Earth and considering the relatively low $\mathrm{S} / \mathrm{N}$, all the observed transitions belong to the main isotopologue ${ }^{40} \mathrm{ArH}^{+}$. Our new measurements concerning the pure rotation 
spectrum of $\mathrm{ArH}^{+}$complete the experimental dataset available in the literature (Brown et al. [12] at low frequency, limited to $J_{\max }^{\prime \prime}=6$, and Liu et al. [23] at higher frequency covering $J^{\prime \prime}=20-22$ ). Table 10 reports the frequencies of the 10 pure rotation transitions assigned in our far-IR spectrum $\mathrm{ArH}^{+}$.

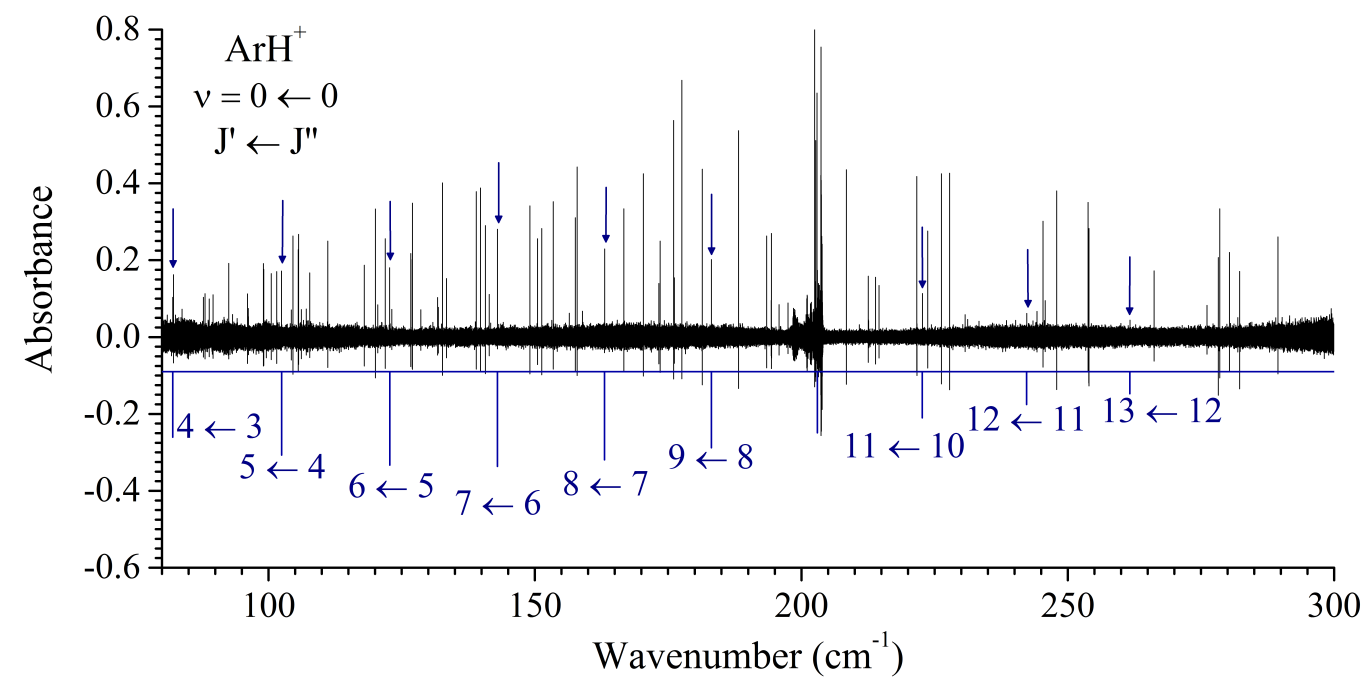

Figure 5: The upper trace shows the pure rotation spectrum of $\mathrm{ArH}^{+}$recorded up to $300 \mathrm{~cm}^{-1}$. Numerous absorption lines due to pure rotation transitions of water are also present in the spectrum. The lower trace is a simulation of $\mathrm{ArH}^{+}$pure rotation spectrum obtained using the parameters published by Bizzocchi et al. [13].

\begin{tabular}{rrrccc}
\hline \hline$J^{\prime}$ & $J^{\prime \prime}$ & Frequencies & $J^{\prime}$ & $J^{\prime \prime}$ & Frequencies \\
\hline \hline 4 & 3 & $82.02280(8)$ & 9 & 8 & $183.10842(8)$ \\
5 & 4 & $102.41727(8)$ & 10 & 9 & $202.98664(8)$ \\
6 & 5 & $122.73767(8)$ & 11 & 10 & $222.71814(8)$ \\
7 & 6 & $142.96942(8)$ & 12 & 11 & $242.28874(8)$ \\
8 & 7 & $163.09782(8)$ & 13 & 12 & $261.68450(8)$ \\
\hline
\end{tabular}

Table 10: Frequencies of the pure rotation transitions of $\mathrm{ArH}^{+}$assigned in our absorption spectrum. Frequencies and uncertainties (expressed in units of the last digits) are given in $\mathrm{cm}^{-1}$.

\subsubsection{Rotation-vibration transitions of the $v=1 \leftarrow 0$ band in the mid-IR}

We recorded the $v=1 \leftarrow 0$ fundamental band of $\mathrm{ArH}^{+}$in the mid-IR region using the experimental conditions described in the previous section. The spectrum corresponds to an average of 30 interferograms recorded at the resolution of $0.008 \mathrm{~cm}^{-1}$. In this spectrum, we assigned 12 transitions in the $P$ branch and 8 transitions in the $R$ branch of the spectrum. 
However, as already mentioned, the set of transitions that we have assigned has already been observed by Brault and Davis [7] by emission spectroscopy with better experimental accuracy.

\section{Conclusions and prospects}

We recorded the pure rotation and rotation-vibration absorption spectra of $3 \mathrm{NgH}^{+}$species, namely $\mathrm{ArH}^{+}, \mathrm{KrH}^{+}$, and $\mathrm{XeH}^{+}$, in the far-IR and mid-IR regions. For both $\mathrm{KrH}^{+}$and $\mathrm{XeH}^{+}$our measurements provided several new measurements which have been added to the dataset available from the literature. The complete linelists, which include pure rotation as well as rotation-vibration spectra of numerous isotopologues, have been fitted using the Dunham Hamiltonian developed in dParFit [35]. Our experimentally determined parameters in this model were compared to calculated values from Ferrante et al. [41] and bond lengths could be re-evaluated with higher precision. In contrast with the study of $\mathrm{KrH}^{+}$ and $\mathrm{XeH}^{+}$, numerous studies from the literature provided a very complete experimental dataset for $\mathrm{ArH}^{+}$and the limited numbers of new lines obtained in our work do not improve the determination of the Dunham's parameters published by Bizzocchi et al. [13].

Because of the limited sensitivity attainable with FTIR spectrometers, pure rotation spectroscopy of ionic species in the $\mathrm{THz}$ and far-IR regions have almost exclusively been performed using both microwave and tunable far-IR laser techniques. To our knowledge, our previous study reporting pure rotation transitions of $\mathrm{HN}_{2}^{+}$using a FTIR spectrometer together with the far-IR synchrotron radiation was the first proof of feasibility of such studies [28]. This new investigation shows our ability to record more high resolution absorption spectra of ionic molecules but these remain in the category of small protonated species. Indeed, the study of ionic molecules with an FTIR instrument is still challenging. As an example, we were unable to detect $\mathrm{NO}^{+}$at SOLEIL while pure rotation lines within the ground and vibrationnally excited states were successfully observed using submillimeter techniques [46]. An interesting perspective to improve the $\mathrm{S} / \mathrm{N}$ of absorption spectra recorded with our rapid scan interferometer of the AILES beamline would be to use modulation concentration or velocity modulation techniques. Following the first demonstration by Martin and Guelachvili [47] using a step-scan interferometer, double modulation techniques have been developed on few continuous scan instruments to perform emission spectroscopy (see e.g. Imajo et al. [48]). Recently, we successfully completed some test experiments in absorption in the mid-IR region. We adapted the concentration modulation 
technique to our apparatus, and we observed an increase of the $\mathrm{S} / \mathrm{N}$ of the $\mathrm{HN}_{2}^{+}$molecular spectrum in comparison with a continuous detection scheme [49]. This new set-up demonstrates that there is room for improvement and shows that there will be interesting opportunities to record pure rotation and/or rotation-vibration absorption spectra of more reactive ionic species using the FTIR interferometer of the AILES beamline.

\section{Acknowledgments}

This work was supported by the Programme National "Physique et Chimie du Milieu Interstellaire" (PCMI) of CNRS/INSU with INC/INP co-funded by CEA and CNES. The authors are very grateful to M.-A. Martin-Drumel for her careful reading of the paper.

\section{Keywords}

astrochemistry, far-infrared, synchrotron radiation, ions, protonated Noble gas, Fouriertransform rotation spectroscopy.

\section{References}

[1] P. Swings and L. Rosenfeld. Considerations regarding interstellar molecules. Astrophysical Journal, 86(4):483-486, 1937. doi: \{10.1086/143880\}.

[2] The astrochemist. http://www. astrochymist.org/

[3] M. J. Barlow, B. M. Swinyard, P. J. Owen, J. Cernicharo, H. L. Gomez, R. J. Ivison, O. Krause, T. L. Lim, M. Matsuura, S. Miller, G. Olofsson, and E. T. Polehampton. Detection of a noble gas molecular ion, ${ }^{36} \mathrm{ArH}^{+}$, in the crab nebula. Science, 342(6164): 1343-1345, 2013. doi: $\{10.1126 /$ science.1243582\}.

[4] P. Schilke, D. A. Neufeld, H. S. P. Mueller, C. Comito, E. A. Bergin, D. C. Lis, M. Gerin, J. H. Black, M. Wolfire, N. Indriolo, J. C. Pearson, K. M. Menten, B. Winkel, A. SanchezMonge, T. Moeller, B. Godard, and E. Falgarone. Ubiquitous argonium (ArH+) in the diffuse interstellar medium: molecular tracer of almost purely atomic gas. Astronomy E Astrophysics, 566, 2014. doi: \{10.1051/0004-6361/201423727\}. 
[5] S. Bovino, M. Tacconi, F. A. Gianturco, and D. Galli. Ion chemistry in the early universe revisiting the role of $\mathrm{HeH}^{+}$with new quantum calculations. Astronomy \& Astrophysics, 529, 2011. doi: $\{10.1051 / 0004-6361 / 201116740\}$.

[6] I. Zinchenko, V. Dubrovich, and C. Henkel. A search for $\mathrm{HeH}^{+}$and $\mathrm{CH}$ in a highredshift quasi-stellar object. Monthly Notices of the Royal Astronomical Society, 415(1): L78-L80, 2011. doi: $\{10.1111 / j .1745-3933.2011 .01083 . x\}$.

[7] J. W. Brault and S. P. Davis. Fundamental vibration-rotation bands and molecularconstants for the $\mathrm{ArH}^{+}$ground-state $\left({ }^{1} \Sigma^{+}\right)$. Physica Scripta, 25(2):268-271, 1982. doi: $\{10.1088 / 0031-8949 / 25 / 2 / 004\}$.

[8] J. W. C. Johns. Spectra of the protonated rare-gases. Journal of Molecular Spectroscopy, 106(1):124-133, 1984. doi: $\{10.1016 / 0022-2852(84) 90087-0\}$.

[9] S. A. Rogers, C. R. Brazier, and P. F. Bernath. The infrared-spectrum of $\mathrm{XeH}^{+}$. Journal of Chemical Physics, 87(1):159-162, 1987. doi: \{10.1063/1.453611\}.

[10] M. Cueto, J. Cernicharo, M. J. Barlow, B. M. Swinyard, V. J. Herrero, I. Tanarro, and J. L. Domenech. New accurate measurement of ${ }^{36} \mathrm{ArH}^{+}$and ${ }^{38} \mathrm{ArH}^{+}$ro-vibrational transitions by high resolution IR absorption spectroscopy. Astrophysical Journal Letters, 783(1), 2014. doi: $\{10.1088 / 2041-8205 / 783 / 1 / L 5\}$.

[11] R. R. Filgueira and C. E. Blom. Observation of vibration-rotation transitions for ${ }^{36} \mathrm{ArH}^{+}$ and ${ }^{38} \mathrm{ArH}^{+}$by diode-laser absorption-spectroscopy. Journal of Molecular Spectroscopy, 127(1):279-280, 1988. doi: $\{10.1016 / 0022-2852(88) 90028-8\}$.

[12] J. M. Brown, D. A. Jennings, M. Vanek, L. R. Zink, and K. M. Evenson. The pure rotational spectrum of $\mathrm{ArH}^{+}$. Journal of Molecular Spectroscopy, 128(2):587-589, 1988. doi: $\{10.1016 / 0022-2852(88) 90173-7\}$.

[13] Luca Bizzocchi, Luca Dore, Claudio Degli Esposti, and Filippo Tamassia. First Laboratory Measurement of the J=1-0 transitions of (ArH+)-Ar-36 and (ArH+)-Ar-38: New, improved rest frequencies for astronomical searches. Astrophysical Journal Letters, 820 (2), 2016. doi: $\{10.3847 / 2041-8205 / 820 / 2 /$ L26\}.

[14] W. C. Bowman, G. M. Plummer, E. Herbst, and F. C. DeLucia. Measurement of the $\mathrm{J}=0-1$ rotational transitions of 3 isotopes of $\mathrm{ArD}^{+}$. Journal of Chemical Physics, 79(4): 2093-2095, 1983. doi: \{10.1063/1.445999\}. 
[15] H. E. Warner, W. T. Conner, and R. C. Woods. The lowest rotational transition of several isotopic forms of $\mathrm{KrD}^{+}$. Journal of Chemical Physics, 81(12):5413-5416, 1984. doi: $\{10.1063 / 1.447640\}$.

[16] K. A. Peterson, R. H. Petrmichl, R. L. McClain, and R. C. Woods. Submillimeter wave spectroscopy of $\mathrm{XeH}^{+}$and $\mathrm{XeD}^{+}$. Journal of Chemical Physics, 95(4):2352-2360, 1991. doi: $\{10.1063 / 1.460941\}$.

[17] Wei-Jo Ting and T. Amano. Submillimeter-wave spectroscopy of $\mathrm{NeD}^{+}, \mathrm{XeH}^{+}$, and $\mathrm{XeD}^{+}$: The Dunham analysis. Chinese Journal of Physics, 52(4):1248-1276, 2014. doi: $\{10.6122 / C J P .52 .1248\}$.

[18] H. Odashima, A. Kozato, F. Matsushima, S. Tsunekawa, and K. Takagi. Far-infrared rotational spectrum of ArD+. Journal of Molecular Spectroscopy, 195(2):356-359, 1999. doi: $\{10.1006 / j m s p .1999 .7832\}$.

[19] H. Linnartz, L. R. Zink, and K. M. Evenson. The pure rotational spectra of ${ }^{84} \mathrm{KrH}^{+}$and ${ }^{86} \mathrm{KrH}^{+}$. Journal of Molecular Spectroscopy, 184(1):56-59, 1997. doi: \{10.1006/jmsp.1997. 7297\}.

[20] H. Odashima, F. Matsushima, A. Kozato, S. Tsunekawa, K. Takagi, and H. Linnartz. Tunable far-infrared spectroscopy of ${ }^{82} \mathrm{KrD}^{+},{ }^{84} \mathrm{KrD}^{+},{ }^{86} \mathrm{KrD}^{+}$, and ${ }^{82} \mathrm{KrH}^{+}$. Journal of Molecular Spectroscopy, 190(1):107-111, 1998. doi: \{10.1006/jmsp.1998.7561\}.

[21] Y. Ohtaki, F. Matsushima, H. Odashima, and K. Takagi. Rotational spectra of $\mathrm{XeH}^{+}$ and its isotopic species. Journal of Molecular Spectroscopy, 210(2):271-274, 2001. doi: $\{10.1006 / j m s p .2001 .8474\}$.

[22] K. B. Laughlin, G. A. Blake, R. C. Cohen, D. C. Hovde, and R. J. Saykally. Determination of the dipole-moment of $\mathrm{ArH}^{+}$from the rotational zeeman effect by tunable far-infrared laser spectroscopy. Physical Review Letters, 58(10):996-999, 1987. doi: $\{10.1103 /$ PhysRevLett.58.996\}.

[23] D. J. Liu, W. C. Ho, and T. Oka. Rotational spectroscopy of molecular-ions using diode-lasers. Journal of Chemical Physics, 87(5):2442-2446, 1987. doi: \{10.1063/1.453084\}.

[24] N. Picque, G. Guelachvili, and S. Civis. Experimental transition dipole moment for the four lowest delta $\mathrm{v}=1$ bands of $\mathrm{ArH}^{+}$in the ${ }^{1} \Sigma^{+}$fundamental state. Journal of Chemical Physics, 113(6):2134-2138, 2000. 
[25] M. A. Martin-Drumel, O. Pirali, D. Balcon, Ph Brechignac, P. Roy, and M. Vervloet. High resolution far-infrared Fourier transform spectroscopy of radicals at the AILES beamline of SOLEIL synchrotron facility. Review of Scientific Instruments, 82(11), 2011. doi: $\{10.1063 / 1.3660809\}$.

[26] M. A. Martin-Drumel, O. Pirali, and M. Vervloet. Synchrotron Based FT-FIR Pure Rotational Spectroscopy of the NH2 Radical in Its Two Lowest Vibrational States. Journal of Physical Chemistry A, 118(8):1331-1338, 2014. doi: \{10.1021/jp406618s\}.

[27] M. A. Martin-Drumel, S. Eliet, O. Pirali, M. Guinet, F. Hindle, G. Mouret, and A. Cuisset. New investigation on $\mathrm{THz}$ spectra of $\mathrm{OH}$ and $\mathrm{SH}$ radicals (X-2 $\mathrm{Pi}(\mathrm{i})$ ). Chemical Physics Letters, 550:8-14, 2012. doi: $\{10.1016 /$ j.cplett.2012.08.027\}.

[28] S. Gruet, A. Morvan, O. Pirali, T. Chamaille, E. Bouisset, and M. Vervloet. Fourier transform far-infrared spectroscopy of HN2+ on the AILES beamline of synchrotron SOLEIL. Canadian Journal of Physics, 91(11, SI):937-940, 2013. doi: \{10.1139/ cjp-2012-0530\}.

[29] R. A. Toth. Water vapor measurements between 590 and $2582 \mathrm{~cm}^{-1}$ : Line positions and strengths. Journal of Molecular Spectroscopy, 190(2):379-396, 1998. doi: \{10.1006/ jmsp.1998.7611\}.

[30] R. Farrenq, G. Guelachvili, A. J. Sauval, N. Grevesse, and C. B. Farmer. Improved dunham coefficients for $\mathrm{CO}$ from infrared solar lines of high rotational-excitation. Journal of Molecular Spectroscopy, 149(2):375-390, 1991. doi: \{10.1016/0022-2852(91) 90293-J\}.

[31] Steve Miller. The Chemical Cosmos: A Guided Tour. Astronomers' Universe. Springer, New York, 2012.

[32] F. Matsushima, T. Oka, and K. Takagi. Observation of the rotational spectra of ${ }^{4} \mathrm{HeH}^{+}$, ${ }^{4} \mathrm{HeD}^{+},{ }^{3} \mathrm{HeH}^{+}$, and ${ }^{3} \mathrm{HeD}^{+}$. Physical Review Letters, 78(9):1664-1666, 1997. doi: \{10. 1103/PhysRevLett.78.1664\}.

[33] M. Wong, P. Bernath, and T. Amano. Observation of the infrared-absorption spectra of ${ }^{20} \mathrm{NeH}^{+}$and ${ }^{22} \mathrm{NeH}^{+}$with a difference frequency laser. Journal of Chemical Physics, 77 (2):693-696, 1982. doi: $\{10.1063 / 1.443883\}$. 
[34] H. M. Pickett. The fitting and prediction of vibration-rotation spectra with spin interactions. J. Mol. Spectrosc., 148(2):371-377, AUG 1991. ISSN 0022-2852. doi: $\{10.1016 / 0022-2852(91) 90393-O\}$.

[35] Robert J. Le Roy. dParFit: A computer program for fitting diatomic molecule spectral data to parameterized level energy expressions. Journal of Quantitative Spectroscopy E Radiative Transfer, 186(SI):197-209, 2017. doi: \{10.1016/j.jqsrt.2016.04.004\}.

[36] A. H. M. Ross, R. S. Eng, and H. Kildal. Heterodyne measurements of ${ }^{12} \mathrm{C}^{18} \mathrm{O},{ }^{13} \mathrm{C}^{16} \mathrm{O}$, and ${ }^{13} \mathrm{C}^{18} \mathrm{O}$ laser frequencies - mass dependence of Dunham coefficients. Optics Communications, 12(4):433-438, 1974. doi: \{10.1016/0030-4018(74)90139-4\}.

[37] J. K. G. Watson. THE ISOTOPE DEPENDENCE OF DIATOMIC DUNHAM COEFFICIENTS. JOURNAL OF MOLECULAR SPECTROSCOPY, 80(2):411-421, 1980. ISSN 0022-2852. doi: $\{10.1016 / 0022-2852(80) 90152-6\}$.

[38] R. J. Le Roy. Improved parameterization for combined isotopomer analysis of diatomic spectra and its application to HF and DF. Journal of Molecular Spectroscopy, 194(2):189196, 1999. doi: \{10.1006/jmsp.1998.7786\}.

[39] P. J. Mohr, B. N. Taylor, and D. B. Newell. The 2014 CODATA Recommended Values of the Fundamental Physical Constants, 2015. URL http://physics.nist.gov/ constants.

[40] P. Rosmus and E. A. Reinsch. Calculation of molecular-constants for the ${ }^{1} \Sigma^{+}$groundstates of the $\mathrm{NeH}^{+}$and $\mathrm{KrH}^{+}$ions. Zeitschrift fur Naturforschung Section A-A Journal of Physical Sciences, 35(10):1066-1070, 1980.

[41] Francesco Ferrante, Giampaolo Barone, and Dario Duca. Relativistic coupled cluster calculations of the electronic structure of $\mathrm{KrH}+, \mathrm{XeH}+$ and $\mathrm{RnH}+$. Theoritical Chemistry Accounts, 131(3), 2012. doi: $\{10.1007 /$ s00214-012-1165-3\}.

[42] R. Klein and P. Rosmus. Calculation of infrared transition-probabilities for the ${ }^{1} \Sigma^{+}$ ground-state of $\mathrm{XeH}^{+}$. Zeitschrift fur Naturforschung Section A-A Journal of Physical Sciences, 39(4):349-353, 1984.

[43] K. B. Laughlin, G. A. Blake, R. C. Cohen, and R. J. Saykally. Experimental-determination of dipole-moments for molecular-ions - improved measurements for $\mathrm{ArH}^{+}$. Journal of Chemical Physics, 90(3):1358-1361, 1989. doi: \{10.1063/1.456077\}. 
[44] K. Lodders. The solar argon abundance. Astrophysical Journal, 674(1):607-611, 2008. doi: $\{10.1086 / 524725\}$.

[45] A G W Cameron. Elemental and isotopic abundances of volatile elements in outer planets. Space Science Reviews, 14(3-4):392-400, 1973. doi: $\{10.1007 / B F 00214750\}$.

[46] J. Cernicharo, S. Bailleux, E. Alekseev, A. Fuente, E. Roueff, M. Gerin, B. Tercero, S. P. Trevino-Morales, N. Marcelino, R. Bachiller, and B. Lefloch. Tentative detection of the nitrosylium ion in space. Astrophysical Journal, 795(1), 2014. doi: $\{10.1088 / 0004-637 X /$ $795 / 1 / 40\}$.

[47] P. A. Martin and G. Guelachvili. Velocity-modulation fourier-transform spectroscopy of molecular ions. Phys. Rev. Lett., 65:2535-2538, 1990. doi: 10.1103/PhysRevLett.65. 2535.

[48] T. Imajo, S. Inui, K. Tanaka, and T. Tanaka. Interferogram amplitude modulation technique for selective detection of transient species with a continuous-scan Fouriertransform spectrometer. Chemical Physics Letters, 274(1-3):99-105, 1997. doi: \{10.1016/ S0009-2614(97)00630-1\}.

[49] Sébastien Gruet. Synchrotron-based high resolution spectroscopic study of protonated species and polycyclic aromatic hydrocarbons in the far-infrared. Univ. Paris-Sud thesis. 2015SACLS049, 2015. URL https://tel .archives-ouvertes. fr/tel-01290024 